\title{
Taxonomic Position of Campylobacter cryaerophila sp. nov.
}

\author{
S. D. NEILL, ${ }^{1 *}$ J. N. CAMPBELL, ${ }^{1}$ J. J. O’BRIEN, ${ }^{1}$ S. T. C. WEATHERUP, ${ }^{2}$ AND W. A. ELLIS ${ }^{1}$ \\ Veterinary Research Laboratories, Stormont, Belfast BT4 3SD, Northern Ireland, ${ }^{1}$ and Agricultural Biometrics Division, \\ Belfast, Northern Ireland ${ }^{2}$
}

\begin{abstract}
A total of 90 aerotolerant Campylobacter strains, which were isolated mainly from animal abortions, were examined by using a wide range of biochemical and physiological tests. The resulting data, together with data for reference Campylobacter strains that were similarly examined, were compared by using several numerical taxonomic analysis methods. Our analyses demonstrated that there is a strong similarity between the aerotolerant strains and strains of Campylobacter fetus, Campylobacter jejuni, Campylobacter coli, and Campylobacter sputorum. For practical purposes this study revealed four possible taxa; one taxon consisted of $C$. fetus strains, one taxon consisted of the $C$. sputorum strains, and a third taxon consisted of the thermophilic strains, having $C$. coli and $C$. jejuni strains as separate entities. The fourth group consisted of all of the aerotolerant strains and was considered a new species of Campylobacter. All of the aerotolerant strains exhibited a tolerance to lower temperatures and higher oxygen concentrations than previously observed with strains of Campylobacter; the name Campylobacter cryaerophila sp. nov. is suggested for these strains. In this paper we present identification characteristics of $C$. cryaerophila strains and a description of the new species.
\end{abstract}

Since the original observation of "Vibrio fetus" in specimens from ovine abortions (40), a variety of microaerophilic vibrios having the same general description have been reported $(2,12,14,16,26,28,34,48,57,60)$. These organisms have been included in the existing genus Campylobacter (54). Of the catalase-positive strains, Campylobacter fetus strains are usually associated with problems of infertility and abortion in domestic animals. However, we have described the recovery of other spiral, Campylobacter-like organisms from abortions in several animal species $(8,9,45)$. These isolates were recovered by using methods and media that are not usually used for Campylobacter isolation. The isolates were tolerant to atmospheric oxygen on subculture and, although assigned to the genus Campylobacter, did not appear to belong to any of the established groups that have been described previously (44).

In the present study, 90 strains recovered from different sources were examined by using physiological and biochemical tests. A numerical taxonomic comparison of these strains and reference Campylobacter strains was made to establish their relationship within the genus Campylobacter and to formulate a scheme for their differentiation.

\section{MATERIALS AND METHODS}

Strains. In this study we used 133 strains, including type and reference strains of some related species (Table 1); 17 of these strains were examined in duplicate to allow us to estimate test error. Most strains had been held for various periods at $-70^{\circ} \mathrm{C}$ or in liquid nitrogen before use, but recently isolated strains were also included. The other reference strains included a "Vibrio percolans" strain, which was representative of aerobic Campylobacter-like organisms isolated from semen (51). The aerotolerant Campylobacter strains are referred to below as undesignated Campylobacter strains.

Culture methods. Preliminary studies established the necessity for using two different culture media and incubation temperatures for maintaining the strains in semisolid media. Strains were subcultured at 1-week intervals during the

\footnotetext{
* Corresponding author.
}

study. Strains isolated by using method B (Table 1) and reference strains $91,92,132$, and 133 were grown at $30^{\circ} \mathrm{C}$ in a medium $(4 \mathrm{ml})$ containing Trypticase soy broth (BBL Microbiology Systems), 0.075\% purified agar, and 1\% hemin solution; the hemin solution was prepared as described by Holdeman and Moore (22). The remaining isolates and reference and type strains were grown at $37^{\circ} \mathrm{C}$ in a medium containing $2.8 \%$ brucella broth (Difco Laboratories), $0.5 \%$ yeast extract, $0.2 \%$ sodium succinate, $0.2 \%$ monosodium glutamate, $0.1 \% \mathrm{MgCl}_{2} \cdot 6 \mathrm{H}_{2} \mathrm{O}, 0.005 \%$ creatine, $0.005 \%$ $\mathrm{FeSO}_{4} \cdot 7 \mathrm{H}_{2} \mathrm{O}, 0.05 \%$ cornstarch, $0.025 \%$ sodium thioglycolate, and $0.16 \%$ agar (B. D. Firehammer, Montana State University, Bozeman, personal communication).

Test media were inoculated from 48- and 72-h growing cultures. Growth in the maintenance media was homogeneously suspended, and dilutions (1:100) made in $0.25 \times$ Ringer solution (Oxoid Ltd.) were used as inocula.

Test procedures. For growth on solid media, we used blood agar base no. 2 (Oxoid) modified by adding $1 \%$ $(\mathrm{vol} / \mathrm{vol})$ hemin as the base medium. Dried plates were inoculated with a multipoint inoculator (Denley Instruments) and, unless otherwise stated, were incubated under reduced oxygen tension $\left(5 \% \quad \mathrm{O}_{2}, 7 \% \mathrm{CO}_{2}, 88 \% \quad \mathrm{~N}_{2}\right)$. Broth and semisolid test media were inoculated with $0.05 \mathrm{ml}$ of inoculum, and the test preparations were incubated in air unless otherwise stated.

Each test was carried out by using a single batch of media, and all strains were tested in duplicate. Strains showing variable results were retested before final results were recorded.

Colony and cell morphology. Cultures grown on $7 \%$ blood agar were examined after 48, 72, and $96 \mathrm{~h}$; colony size and shape were recorded. Smears were Gram stained when colonies become visible, usually after $48 \mathrm{~h}$. Motility and morphology were determined by using dark-field microscopy. Cultures growing in semisolid medium were also examined by using dark-field microscopy.

Pigmentation. Cultures grown on blood agar and on base medium were examined for pigment production by smearing colonies onto white filter paper. Pigment production on King media A and B (29) was also tested.

Hemolysis. Hemolysis ability was tested at both 37 and $30^{\circ} \mathrm{C}$ by culturing organisms for 4 days on blood agar base 
TABLE 1. Strains examined in this study

\begin{tabular}{|c|c|c|c|c|c|}
\hline $\begin{array}{l}\text { Labora- } \\
\text { tory no. }\end{array}$ & Strain & Taxon & $\begin{array}{l}\text { Isolation } \\
\text { method(s) }\end{array}$ & Origin & Source $^{b}$ \\
\hline 1 & $\mathrm{~A} 102 / \mathrm{Pt}$ & & B & Peritoneal fluid; aborted bobine fetus & VRLB \\
\hline 2 & A171/Eye & & $\mathrm{B}$ & Aqueous humor; aborted bovine fetus & VRLB \\
\hline 3 & $\mathrm{~A} 175 / \mathrm{K}$ & & $\mathrm{B}$ & Kidney; aborted bovine fetus & VRLB \\
\hline 4 & A175/P & & B & Placenta: bovine abortion & VRLB \\
\hline 5 & $\mathrm{~A} 169 / \mathrm{B}^{\mathrm{T}}$ & & $\mathrm{B}$ & Brain; aborted bovine fetus & VRLB \\
\hline 6 & A169/P & & $\mathrm{B}$ & Placenta: bovine abortion & VRLB \\
\hline 7 & $\mathrm{~A} 174 / \mathrm{K}$ & & $\mathrm{B}$ & Kidney; aborted bovine fetus & VRLB \\
\hline 8 & A174/P & & $\mathrm{B}$ & Placenta; bovine abortion & VRLB \\
\hline 9 & $\mathrm{~A} 179 / \mathrm{T}$ & & $\mathrm{B}$ & Thoracic fluid; aborted bovine fetus & VRLB \\
\hline 10 & $\mathrm{~B} 2656 / \mathrm{U}$ & & B & Aborted bovine fetus & VRLB \\
\hline 11 & $\mathrm{~A} 128 / \mathrm{Pc}$ & & $\mathrm{B}$ & Pericardial fluid; aborted bovine fetus & VRLB \\
\hline 12 & A182/FB & & B & Blood; aborted bovine fetus & VRLB \\
\hline 13 & $\mathrm{~B} 816 / \mathrm{T}$ & & B & Thoracic fluid; aborted bovine fetus & VRLB \\
\hline 14 & N1033/P & & $\mathrm{B}$ & Bovine placenta & VRLB \\
\hline 15 & $\mathrm{~A} 191 / \mathrm{Pt}$ & & $\mathrm{B}$ & Peritoneal fluid; aborted bovine fetus & VRLB \\
\hline 16 & $\mathrm{~N} 1049 / \mathrm{K}$ & & B & Bovine fetal kidney & VRLB \\
\hline 17 & $\mathrm{~N} 1059 / \mathrm{P}$ & & B & Bovine placenta & VRLB \\
\hline 18 & $\mathrm{~N} 1031 / \mathrm{P}$ & & $\mathrm{B}$ & Bovine placenta & VRLB \\
\hline 19 & $\mathrm{~N} 1058 / \mathrm{P}$ & & $\mathrm{B}$ & Bovine placenta & VRLB \\
\hline 20 & $\mathrm{~B} 2188 / \mathrm{Am}$ & & $\mathrm{B}$ & Amniotic fluid; aborted bovine fetus & VRLB \\
\hline 21 & $\mathrm{~B} 2211 / \mathrm{Sc}$ & & $\mathrm{B}$ & Stomach contents; aborted bovine fetus & VRLB \\
\hline 22 & $\mathrm{~B} 207 / \mathrm{T}$ & & B & Thoracic fluid; aborted bovine fetus & VRLB \\
\hline 23 & $\mathrm{~N} 1054 / \mathrm{Am}$ & & $\mathrm{B}$ & Bovine amniotic fluid & VRLB \\
\hline 24 & B2016/K & & $\mathrm{B}$ & Kidney; aborted bovine fetus & VRLB \\
\hline 25 & $\mathrm{~B} 955 / \mathrm{P}$ & & B & Placenta; bovine abortion & VRLB \\
\hline 26 & $\mathrm{~B} 3091 / \mathrm{Pt}$ & & $A$ and $B$ & Peritoneal fluid; aborted bovine fetus & VRLB \\
\hline 27 & B698/B & & $A$ and $B$ & Brain; aborted bovine fetus & VRLB \\
\hline 28 & B2767/P & & $A$ and $B$ & Placenta; bovine abortion & VRLB \\
\hline 29 & B109(A)/Eye & & B & Aqueous humor; aborted bovine fetus & VRLB \\
\hline 30 & B3493/F & & B & Bovine feces & VRLB \\
\hline 31 & B3494/F & & $\mathrm{B}$ & Bovine feces & VRLB \\
\hline 32 & B3495/F & & B & Bovine feces & VRLB \\
\hline 33 & $\mathrm{~B} 3592 / \mathrm{F}$ & & B & Bovine feces & VRLB \\
\hline 34 & $\mathrm{~B} / 2$ & & $\mathrm{~B}$ & Bovine feces & VRLB \\
\hline 35 & $\mathrm{~B} / 53$ & & $\mathrm{~B}$ & Bovine feces & VRLB \\
\hline 36 & $\mathrm{LC} 78 / 35 / 4$ & & $\mathrm{~B}$ & Milk; bovine mastitis & CVLW \\
\hline 37 & LC78/49 & & B & Kidney; aborted bovine fetus & CVLW \\
\hline 38 & S613(a)/Eye & & B & Aqueous humor: aborted porcine fetus & VRLB \\
\hline 39 & S613(b)/Eye & & B & Aqueous humor: aborted porcine fetus & VRLB \\
\hline 40 & S836/Eye & & B & Aqueous humor; aborted porcine fetus & VRLB \\
\hline 41 & B1904/K & & B & Kidney; aborted porcine fetus & VRLB \\
\hline 42 & S368/K & & B & Kidney; aborted porcine fetus & VRLB \\
\hline 43 & $\mathrm{~B} 2075 / \mathrm{Sc}$ & & B & Stomach contents: aborted porcine fetus & VRLB \\
\hline 44 & $\mathrm{~B} 1963 / \mathrm{Sc}$ & & B & Stomach contents; aborted porcine fetus & VRLB \\
\hline 45 & B2601/P & & B & Placenta: porcine abortion & VRLB \\
\hline 46 & $\mathrm{~B} 2385 / \mathrm{Sc}$ & & B & Stomach contents; aborted porcine fetus & VRLB \\
\hline 47 & S1010/Eye & & B & Aqueous humor; aborted porcine fetus & VRLB \\
\hline 48 & $\mathrm{~S} 314 / \mathrm{T}$ & & B & Thoracic fluid; aborted porcine fetus & VRLB \\
\hline 49 & S568/Eye & & B & Aqueous humor: aborted porcine fetus & VRLB \\
\hline 50 & $\mathrm{~B} 789 / \mathrm{L}$ & & B & Liver; aborted porcine fetus & VRLB \\
\hline 51 & B1019 & & B & Aborted porcine fetus & VRLB \\
\hline 52 & B1049/P & & B & Placenta; porcine abortion & VRLB \\
\hline 53 & $\mathrm{~S} 314 / \mathrm{P}$ & & B & Placenta; porcine abortion & VRLB \\
\hline 54 & $\mathrm{~B} 2582 / \mathrm{Sc}$ & & B & Stomach contents; aborted porcine fetus & VRLB \\
\hline 55 & $\mathrm{~B} 99 / \mathrm{Sc}$ & & B & Stomach contents; aborted porcine fetus & VRLB \\
\hline 56 & $\mathrm{~B} 288 / \mathrm{N}$ & & B & Umbilical swab; aborted porcine fetus & VRLB \\
\hline 57 & $\mathrm{~B} 237 / \mathrm{Sc}$ & & B & Stomach contents; aborted procine fetus & VRLB \\
\hline 58 & $\mathrm{~B} 453 / \mathrm{P}$ & & B & Placenta; porcine abortion & VRLB \\
\hline 59 & $\mathrm{~B} 396 / \mathrm{P}$ & & B & Placenta: porcine abortion & VRLB \\
\hline 60 & B1018 & & B & Aborted porcine fetus & VRLB \\
\hline 61 & B2331/P & & B & Placenta; porcine abortion & VRLB \\
\hline 62 & $\mathrm{~B} 2268 / \mathrm{Sc}$ & & B & Stomach contents; aborted porcine fetus & VRLB \\
\hline 63 & $\mathrm{~B} 3077 / \mathrm{T}$ & & $A$ and $B$ & Thoracic fluid; aborted porcine fetus & VRLB \\
\hline 64 & $\mathrm{~B} 243 / \mathrm{P}$ & & $\mathrm{A}$ and $\mathrm{B}$ & Placenta; porcine abortion & VRLB \\
\hline 65 & B244(b)/B & & $\mathrm{A}$ and $\mathrm{B}$ & Brain; aborted porcine fetus & VRLB \\
\hline 66 & B464/Eye & & $\mathrm{A}$ and $\mathrm{B}$ & Aqueous humor; aborted porcine fetus & VRLB \\
\hline 67 & $\mathrm{~B} 465 / \mathrm{K}$ & & $A$ and $B$ & Kidney; aborted porcine fetus & VRLB \\
\hline 68 & $\mathrm{~B} 1508 / \mathrm{B}$ & & $A$ and $B$ & Brain; aborted porcine fetus & VRLB \\
\hline
\end{tabular}


TABLE 1-Continued

\begin{tabular}{|c|c|c|c|c|c|}
\hline $\begin{array}{l}\text { Labora- } \\
\text { tory no. }\end{array}$ & Strain & Taxon & $\begin{array}{c}\text { Isolation } \\
\text { method(s) }\end{array}$ & Origin & Source $^{h}$ \\
\hline 69 & $\mathrm{~B} 2346 / \mathrm{Sc}$ & & $A$ and $B$ & Stomach contents; aborted porcine fetus & VRLB \\
\hline 70 & $\mathrm{~B} 986 / \mathrm{T}$ & & B & Thoracic fluid; aborted porcine fetus & VRLB \\
\hline 71 & $\mathrm{~B} 1066 / \mathrm{P}$ & & B & Placenta; porcine abortion & VRLB \\
\hline 72 & $\mathrm{~B} 1171 / \mathrm{P}$ & & B & Placenta; porcine abortion & VRLB \\
\hline 73 & $\mathrm{~B} 463 / \mathrm{T}$ & & B & Thoracic fluid; aborted porcine fetus & VRLB \\
\hline 74 & $\mathrm{C} / 79 / \mathrm{Q}$ & & B & Aborted porcine fetus & UM \\
\hline 75 & $\mathrm{LC} 78 / 35 / 1$ & & B & Stillborn piglet & CVLW \\
\hline 76 & $\mathrm{LC} 78 / 35 / 2$ & & $\mathrm{~B}$ & Stillborn piglet & CVLW \\
\hline 77 & $\mathrm{LC} 78 / 35 / 3$ & & B & Stillborn piglet & CVLW \\
\hline 78 & B3286/F & & $\mathrm{B}$ & Porcine feces & VRLB \\
\hline 79 & $\mathrm{~B} 3497 / \mathrm{F}$ & & $\mathrm{B}$ & Porcine feces & VRLB \\
\hline 80 & B3540/F & & $\mathrm{B}$ & Porcine feces & VRLB \\
\hline 81 & $\mathrm{~B} 750 / \mathrm{P}$ & & $\mathrm{B}$ & Placenta; ovine abortion & VRLB \\
\hline 82 & $\mathrm{~B} 858 / \mathrm{P}$ & & $\mathrm{B}$ & Placenta; ovine abortion & VRLB \\
\hline 83 & B938 & & $\mathrm{B}$ & Placenta; ovine abortion & VRLB \\
\hline 84 & B1056 & & B & Aborted ovine fetus & VRLB \\
\hline 85 & B391/K & & B & Kidney; aborted ovine fetus & VRLB \\
\hline 86 & B3525/FB & & B & Blood; aborted ovine fetus & VRLB \\
\hline 87 & B3426/T & & B & Thoracic fluid; aborted ovine fetus & VRLB \\
\hline 88 & B3387/P & & $\mathrm{B}$ & Placenta; ovine abortion & VRLB \\
\hline 89 & B837/S & & B & Spleen; aborted equine fetus & VRLB \\
\hline 90 & $\mathrm{LC} 78 / 35 / 5$ & & B & Kidney; dog & VRLB \\
\hline 91 & 8193 & "V. percolans" & & & NCIB \\
\hline 92 & $17802^{\mathrm{T}}$ & V. parahaemolyticus & & & ATCC \\
\hline 93 & 1380 & $\begin{array}{l}\text { C. fetus subsp. jejuni or } \\
\text { V. coli }\end{array}$ & & Porcine fetus & TIGU \\
\hline 94 & 10354 & C. fetus biotype A & & Bovine vaginal mucus & NCTC \\
\hline 95 & 6945 & C. fetus subsp. venerealis & & Bovine prepuce & CIP \\
\hline 96 & 5419 & C. fetus subsp. venerealis & & Bovine vagina & CIP \\
\hline 97 & 18011 & C. fetus group A, biotype & & Bovine cervical mucus & MSU \\
\hline 98 & 5443 & $\begin{array}{l}C . \text { fetus subsp. venerealis } \\
\text { biotype intermedius }\end{array}$ & & Human blood & CIP \\
\hline 99 & 5399 & $\begin{array}{l}\text { C. fetus subsp. venerealis } \\
\text { biotype intermedius }\end{array}$ & & Human blood & CIP \\
\hline 100 & 13831 & $\begin{array}{l}\text { C. fetus subsp. venerealis } \\
\text { biotype intermedius }\end{array}$ & & Bovine fetus & MSU \\
\hline 101 & 12351 & $\begin{array}{l}\text { Vibrio fetus subsp. } \\
\text { intestinalis group A, } \\
\text { biotype } 2\end{array}$ & & Ovine fetus & MSU \\
\hline 102 & 688 & C. fetus subsp. fetus & & Bovine prepuce & CIP \\
\hline 103 & A168 & C. fetus subsp. fetus & & Human blood & CIP \\
\hline 104 & $5396^{\mathrm{T}}$ & C. fetus subsp. fetus & & Ovine fetus & CIP \\
\hline 105 & 6944 & C. fetus subsp. fetus & & Bovine prepuce & CIP \\
\hline 106 & 13136 & $\begin{array}{l}\text { Vibrio fetus subsp. } \\
\text { intestinalis group C }\end{array}$ & & Ovine fetus & MSU \\
\hline 107 & 10348 & C. fetus biotype B & & Bovine vaginal mucus & NCTC \\
\hline 108 & 10355 & $\begin{array}{l}\text { C. sputorum subsp. } \\
\text { bubulus }\end{array}$ & & Bovine semen & NCTC \\
\hline 109 & $53103^{\mathrm{T}}$ & $\begin{array}{l}\text { C. sputorum subsp. } \\
\text { bubulus }\end{array}$ & & Bovine sperm & CIP \\
\hline 110 & $7080^{\mathrm{T}}$ & C. coli & & Porcine feces & CIP \\
\hline 111 & 7054 & C. coli & & Porcine feces & CIP \\
\hline 112 & $99 / 888$ & C. coli or $C$. jejuni & & Human feces & $\mathrm{CHE}$ \\
\hline 113 & $99 / 965$ & C. coli or C. jejuni & & Human feces & $\mathrm{CHE}$ \\
\hline 114 & $702^{\mathrm{T}}$ & C. jejlani & & Bovine feces & CIP \\
\hline 115 & $\mathrm{BP} / 0065$ & $C$. coli or $C$. jejuni & & Human feces & BPHB \\
\hline 116 & $\mathrm{BP} / 1663$ & C. coli or C. jejuni & & Human feces & BPHB \\
\hline 117 & $\mathrm{~A} 29 / \mathrm{F}$ & C. fetus & A & Feces; aborting cow & VRLB \\
\hline 118 & $\mathrm{~A} 70 / \mathrm{P}$ & C. fetus & A & Placenta; bovine abortion & VRLB \\
\hline 119 & $\mathrm{~A} 178 / \mathrm{F}$ & C. fetus & A & Feces; aborting cow & VRLB \\
\hline 120 & $\mathrm{~N} 1022 / \mathrm{F}$ & C. fetus & A & Bovine feces & VRLB \\
\hline 121 & $\mathrm{~N} 1023 / \mathrm{F}$ & C. fetus & A & Bovine feces & VRLB \\
\hline 122 & $\mathrm{~N} 1014 / \mathrm{F}$ & C. fetus & A & Bovine feces & VRLB \\
\hline 123 & $\mathrm{~A} 36 / \mathrm{F}$ & C. fetus & A & Feces; aborting cow & VRLB \\
\hline 124 & $\mathrm{~A} 158 / \mathrm{F}$ & C. fetus & A & Feces; aborting cow & VRLB \\
\hline 125 & $\mathrm{~A} 128 / \mathrm{F}$ & C. fetus & A & Feces; aborting cow & VRLB \\
\hline 126 & $\mathrm{~A} 192 / \mathrm{P}$ & C. fetus & A & Placenta; bovine abortion & VRLB \\
\hline
\end{tabular}


TABLE 1-Continued

\begin{tabular}{|c|c|c|c|c|c|}
\hline $\begin{array}{l}\text { Labora- } \\
\text { tory no. }\end{array}$ & Strain & Taxon & $\begin{array}{l}\text { Isolation } \\
\text { method(s) }\end{array}$ & Origin & Source ${ }^{b}$ \\
\hline 127 & $\mathrm{~A} 87 / \mathrm{V}$ & C. fetus & A & Vaginal mucus; bovine abortion & VRLB \\
\hline 128 & $\mathrm{~N} 1022 / \mathrm{V}$ & C. fetus & A & Vaginal mucus; bovine & VRLB \\
\hline 129 & $\mathrm{~N} 1020 / \mathrm{F}$ & C. fetus & A & Feces; bovine & VRLB \\
\hline 130 & $\mathrm{~A} 163 / \mathrm{F}$ & C. fetus & A & Feces; aborting cow & VRLB \\
\hline 131 & $\mathrm{~A} 70 / \mathrm{F}$ & C. fetus & A & Feces; aborting cow & VRLB \\
\hline 132 & NCIB 9072 & A. polymorphum & & Pond water & NCIB \\
\hline 134 & $\mathrm{~A} 102 / \mathrm{Pt}$ & & B & Peritoneal fluid; aborted bovine fetus & VRLB \\
\hline 135 & A171/Eye & & B & Aqueous humor; aborted bovine fetus & VRLB \\
\hline 136 & $\mathrm{~A} 175 / \mathrm{K}$ & & B & Kidney; aborted bovine fetus & VRLB \\
\hline 137 & $\mathrm{~S} 613(\mathrm{a}) / \mathrm{E}$ & & B & Aqueous humor; aborted bovine fetus & VRLB \\
\hline 138 & S613(b)/E & & B & Aqueous humor: aborted bovine fetus & VRLB \\
\hline 139 & $\mathrm{~B} 750 / \mathrm{P}$ & & B & Placenta; ovine abortion & VRLB \\
\hline 140 & 10354 & C. fetus biotype $\mathrm{A}$ & & Bovine vaginal mucus & NCTC \\
\hline 141 & $5396^{\top}$ & C. fetus subsp. fetus & & Bovine prepuce & CIP \\
\hline 143 & 7080 & C. coli & & Porcine feces & CIP \\
\hline 144 & $\mathrm{~A} 29 / \mathrm{F}$ & C. fetus & A & Bovine feces & VRLB \\
\hline 145 & $\mathrm{~A} 70 / \mathrm{P}$ & C. fetus & A & Placenta; bovine abortion & VRLB \\
\hline 146 & $702^{\mathrm{T}}$ & C. jejuni & & Bovine feces & CIP \\
\hline 147 & $\mathrm{~B} 858 / \mathrm{P}$ & & B & Placenta; ovine abortion & VRLB \\
\hline 148 & $\mathrm{~S} 836 / \mathrm{E}$ & & B & Aqueous humor; aborted bovine fetus & VRLB \\
\hline 149 & $\mathrm{~A} 70 / \mathrm{F}$ & C. fetus & A & Bovine feces & VRLB \\
\hline 150 & $\mathrm{~A} 128 / \mathrm{Pc}$ & & B & Pericardial fluid; aborted bovine fetus & VRLB \\
\hline
\end{tabular}

"See reference 46 .

b ATCC, American Type Culture Collection, Rockville, Md.; BPHB, Belvoir Park Hospital, Belfast, Northern Ireland; CHE, City Hospital, Edinburgh, Scotland; CIP. Collection d'Institut Pasteur. Paris, France: CVLW: Central Veterinary Laboratories. Weybridge. England; MSU, Montana Site University, Bozeman; NCIB, National Collection of Industrial Bacteria, Aberdeen, Scotland; NCTC, National Collection of Type Cultures, London, England; TIGU, Tierarztliches Institut, Göttingen University, Göttingen, Federal Republic of Germany: VRLB, Veterinary Research Laboratories, Belfast, Northern Ireland; UM, University of Montreal, Montreal, Canada.

no. 2 containing $7 \%$ sterile blood (human, bovine, equine, ovine, caprine, and porcine).

Growth on different media. Strains were tested for growth on MacConkey agar (Oxoid), deoxycholate-citrate agar (Oxoid), brucella agar (Oxoid), cysteine heart agar (Difco), brain heart infusion agar (Oxoid), blood agar base no. 2 (Oxoid), and EMJH medium (Difco) containing 1.2\% agar. Plates were examined for up to 4 days.

Growth at different temperatures. Growth on the base medium and on $7 \%$ horse blood agar at 5, 10, 15, 20, 22, 25, $30,33,35,37,40,42$, and $43 \pm 0.5^{\circ} \mathrm{C}$ was recorded for up to 7 days.

pH. Growth on the base medium at initial $\mathrm{pH}$ values which ranged from 5.0 to 11.0 in $0.5 \mathrm{pH}$ unit intervals was recorded. Inoculated plates were incubated for up to 4 days.

Growth in different atmospheres. All strains were examined for up to 7 days for growth on the base medium and on horse blood agar in air, in air containing $10 \% \mathrm{CO}_{2}$, under reduced oxygen tension $\left(5 \% \mathrm{O}_{2}, 7 \% \mathrm{CO}_{2}, 88 \% \mathrm{~N}_{2}\right)$, and under anaerobic conditions $\left(12 \% \mathrm{H}_{2}, 8 \% \mathrm{CO}_{2}, 80 \% \mathrm{~N}_{2}\right.$, in the presence of a palladium catalyst).

Catalase test. Catalase activity was determined (15) by using 48-h cultures grown in semisolid maintenance medium.

Oxidase test. Oxidase activity was determined (31) by using 48-h cultures grown on base medium.

Indole production. Cultures grown in Trypticase soy semisolid medium were examined for indole production by using method 2 of Cowan (7).

Methyl red and Voges-Proskauer tests. The methyl red test was performed by the method of Cowan (7), and the VogesProskauer test was performed by method 1 of Cowan (7).

Nitrate and nitrite reduction. Cultures incubated for 7 days in Trypticase soy semisolid medium containing $0.1 \%$ (wt $/ \mathrm{vol}$ ) $\mathrm{KNO}_{3}$ were examined for nitrate and nitrite reduction by using method 1 of Cowan (7). Cultures grown for 7 days in Trypticase soy semisolid medium containing $0.1 \%(\mathrm{wt} / \mathrm{vol})$ $\mathrm{NaNO}_{2}$ were also examined for nitrite reduction (7).

Decarboxylase activity. Cultures grown in Moller medium (42) and Falkow medium (10) modified to contain $0.075 \%$ purified agar and supplemented with either $1 \%(\mathrm{wt} / \mathrm{vol})$ lysine, $1 \%(\mathrm{wt} / \mathrm{vol})$ ornithine, or $1 \%(\mathrm{wt} / \mathrm{vol})$ arginine were examined for decarboxylase activity after 7 days by using methods 1 and 2 of Cowan (7).

$\beta$-Galactosidase production. The method of Cowan (7) was used to examine $\beta$-galactosidase activity. Agar $(0.075 \%$, $\mathrm{wt} / \mathrm{vol}$ ) was added to $o$-nitrophenyl- $\beta$-D-galactopyranoside broth.

Urease production. Method 1 of Cowan (7) was used to examine strains for urease activity. Slants of Christensen medium (6) were inoculated with a heavy inoculum, incubated under reduced oxygen tension, and examined after 4 days.

Deoxyribonuclease production. Deoxyribonuclease test agar (Oxoid) was examined after 4 days for enzyme activity, which appeared as a clear zone around the area of bacterial growth after the medium was flooded with $1 \mathrm{~N} \mathrm{HCl}$.

Phosphatase production. Medium containing blood agar base no. 2 as the base medium and method 1 of Cowan (7) were used to determine phosphatase activity after 4 days.

Hydrogen sulfide production. Strains were examined for $\mathrm{H}_{2} \mathrm{~S}$ production in triple sugar iron medium by using method 1 of Cowan (7) and in standard and sensitive media by using the method of Véron and Chatelain (62).

Tributyrin hydrolysis. Inoculated plates of tributyrin agar 
(Oxoid) were examined for zones of clearing for up to 7 days. The growth was then removed, and the underlying agar was examined for clearing.

Casein hydrolysis. The medium of Cowan (7), modified by using blood agar base no. 2, was used to determine casein hydrolysis; hydrolysis was determined as described above for tributyrin hydrolysis.

Starch hydrolysis. The medium of Cowan (7), modified by using blood agar base no. 2, was used to determine starch hydrolysis. Plates were incubated for 4 days, and hydrolysis was determined by method 1 of Cowan (7).

Esculin hydrolysis. The method and medium of Cowan (7) were used to determine esculin hydrolysis; hydrolysis was recorded after 4 days.

Hippurate hydrolysis. The medium and method 2 of Cowan (7) were used to determine hippurate hydrolysis for up to 7 days.

Gelatin hydrolysis. Blood agar base no. 2 and method 3 of Cowan (7) were used to detect gelatin hydrolysis after 4 days.

Serum liquefaction. The medium and method of Cowan (7) were used to determine serum liquefaction; the results were recorded after 7 days.

Decomposition of tyrosine. The method and medium of Cowan (7) were used to test for decomposition of tyrosine; the plates were examined after 14 days of incubation.

Citrate utilization. Koser and Simmons citrate media containing $0.075 \%$ agar and methods 1 and 2 of Cowan (7) were used to determine citrate utilization. The media were incubated in air for 7 days.

Malonate utilization. Method 1 of Cowan (7), modified so that the medium contained $0.075 \%$ agar, was used to determine malonate utilization. Cultures were incubated in air for 7 days.

Gluconate oxidation. The medium of Cowan (7), modified so that it contained $0.075 \%$ agar, was used to determine gluconate oxidation. Cultures were incubated in air for 7 days; Labstix (Ames Co. and Miles Laboratories) and method 2 of Cowan (7) were used.

Oxidative or fermentative utilization of glucose. The method and medium of Hugh and Leifson (23) were used to determine oxidative or fermentative utilization of glucose.

Phenylalanine deamination. Malonate-phenylalanine medium containing $0.075 \%$ agar and method 1 of Cowan (7) were used to study phenylalanine deamination.

Reaction in milk. Litmus milk (7) and Crossley milk (Oxoid) were incubated under reduced oxygen tension and read after 7 days.

Growth in potassium cyanide agar. KCN broth (50) containing $0.075 \%$ agar and the method of Cowan (7) were used to determine growth in potassium cyanide agar. Cultures were incubated in air for 7 days.

Tolerance tests. Plates of basal medium containing the following compounds were examined after 7 days: acriflavine $(0.002,0.001$, and $0.0005 \%, \mathrm{wt} / \mathrm{vol})$; azaguanine $(0.01,0.025,0.05,0.2,0.12,0.15,0.2$, and $0.25 \%, \mathrm{wt} / \mathrm{vol})$; basic fuchsin $(0.002,0.001$, and $0.0005 \%$, wt $/$ vol $)$; bile salts $(0.1,0.5,1.0$, and $2.0 \%$, wt/vol; Oxoid); bile salt no. $3(0.1$, $0.5,1.0$, and $2.0 \%$, wt $/$ vol; Oxoid); bile ( $1 \%$, wt/vol; Oxoid); brilliant green $(0.004,0.002,0.001,0.0005$, and $0.00025 \%$, $\mathrm{wt} / \mathrm{vol}$; Difco); cetrimide $(0.1,0.01$, and $0.001 \%, \mathrm{wt} / \mathrm{vol})$; copper sulfate $(0.01,0.001$, and $0.0001 \%, w t / v o l)$; crystal violet $(0.01,0.001$, and $0.0001 \%$, wt $/ \mathrm{vol})$; glycine $(0.1,0.5$, 1.0 , and $1.5 \%$, wt/vol $)$ glucose $(2,4,6,8$, and $10 \%, \mathrm{wt} / \mathrm{vol})$; lysozyme $(0.05,0.005$, and $0.0025 \%$, wt $/ \mathrm{vol})$; methyl violet $(0.01,0.002$, and $0.001 \%, \mathrm{wt} / \mathrm{vol})$; malachite green $(0.002$,
0.001 , and $0.005 \%$, wt $/ \mathrm{vol})$; potassium tellurite $(0.01$ and $0.001 \%)$, pyronine $(0.001,0.00005$, and $0.00001 \%$; wt/vol); safranin $(0.05,0.01$, and $0.001 \%$, wt $/ \mathrm{vol})$; sodium azide $(0.01$ and $0.001 \%$, wt/vol); sodium chloride $(1,1.5,2.0,2.5,3.0$, 3.5 , and $5 \%, \mathrm{wt} / \mathrm{vol})$; sodium lauryl sulfate $(0.01,0.1$, and $1.0 \%, \mathrm{wt} / \mathrm{vol})$; sodium selenite $(0.01,0.05,0.1$, and $0.5 \%$, $\mathrm{wt} / \mathrm{vol})$; thallous acetate $(0.01$ and $0.001 \%$, wt/vol $)$; thionine $(0.002,0.001$, and $0.0005 \%$, wt/vol $) ; 2,3,5$-triphenyl tetrazolium chloride $(0.01,0.025,0.05$, and $0.1 \%$, wt $/ \mathrm{vol})$; and vibriostatic compound 0/129 (2,4-diamino-6,7-diisopropylpteridine; $1 \%, \mathrm{wt} / \mathrm{vol}$ ).

The following antibiotics were used (the ranges of concentration were prepared in doubling dilutions [e.g., 1/2, 1/4, etc.]): ampicillin $(0.5$ to $32 \mu \mathrm{g} / \mathrm{ml})$; carbenicillin ( 2.0 to 256 $\mu \mathrm{g} / \mathrm{ml}$ ); chloramphenicol (1 to $16 \mu \mathrm{g} / \mathrm{ml})$; dimetridazole $(0.125$ to $128 \mu \mathrm{g} / \mathrm{ml})$; kanamycin $(1,2$, and $4 \mu \mathrm{g} / \mathrm{ml})$; metronidazole $(0.125$ to $128 \mu \mathrm{g} / \mathrm{ml})$; nalidixic acid ( 5 to $40 \mu \mathrm{g} / \mathrm{ml}$ ); penicillin $\mathrm{G}(0.75$ and $1.5 \mathrm{IU} / \mathrm{ml})$; polymyxin $\mathrm{B}$ (1 to 128 $\mu \mathrm{g} / \mathrm{ml})$, and streptomycin $(12.5,25$, and $50 \mu \mathrm{g} / \mathrm{ml})$.

Tolerance tests were performed as described by Véron and Chatelain (62) for the following compounds: glucose $(8 \%, \mathrm{wt} / \mathrm{vol})$, glycine $(1 \%, \mathrm{wt} / \mathrm{vol}), \mathrm{NaCl}(3.5 \%, \mathrm{wt} / \mathrm{vol})$, ox bile $(1 \%, \mathrm{wt} / \mathrm{vol})$, sodium selenite $(0.1 \%, \mathrm{wt} / \mathrm{vol})$, brilliant green $(0.001$ and $0.003 \%, \mathrm{wt} / \mathrm{vol}), 2,3,5$-triphenyl tetrazolium chloride $(1 \mathrm{mg} / \mathrm{ml})$, and nalidixic acid $(40 \mu \mathrm{g} / \mathrm{ml})$.

Acid from carbohydrates. Broth sugar medium (7) containing $0.075 \%$ agar and $0.002 \%(\mathrm{wt} / \mathrm{vol}$ ) bromocresol purple as an indicator was used to study acid production from carbohydrates. Filter-sterilized carbohydrates were added aseptically to final concentrations of $1.0 \%$ (wt $/ \mathrm{vol}$ ). Starch, esculin, and glycogen were added before autoclaving. Duplicate samples were inoculated; one was layered with liquid paraffin, and both were incubated in air for up to 14 days. Acid production was scored as positive; no growth or no reaction was scored as negative. The following carbohydrates were used: esculin, L-arabinose, cellobiose, dextrin, erythritol, D-fructose, D-galactose, galactitol, Dglucitol, D-glucose, glycogen, meso-inositol, lactose, maltose, D-mannitol, D-mannose, melibiose, raffinose, Dribose, ribitol, starch, sucrose, trehalose, and D-xylose.

Nutritional requirements. Carbon utilization tests were performed by using yeast nitrogen base agar (Difco). The carbon sources were sterilized as $5 \%$ solutions at $100^{\circ} \mathrm{C}$ for 1 $\mathrm{h}$ on 3 consecutive days or by filtration and were added to the base medium at final concentrations of 0.01 to $0.1 \%$ $(\mathrm{wt} / \mathrm{vol}$ or $\mathrm{vol} / \mathrm{vol})$. The media were dispensed into sectioned plates (Sterilin). Dry plates were inoculated by using a multipoint inoculator and were incubated under reduced oxygen tension. Growth was assessed for up to 14 days. Yeast nitrogen base medium containing no carbon source was used as a control. Horse blood agar was replica-plated at the beginning and end of each inoculation to check strain growth and to check for contaminants. The following compounds were used as sole sources of carbon: D-arabinose, L-arabinose, cellobiose dextrin, erythritol, D-fructose, Dgalactose, D-glucose, D-glucitol, glycogen, glycerol, lactose, maltose, D-mannitol, D-mannose, melezitose, melibiose, raffinose, L-rhamnose, ribitol, salicin, starch, sucrose, trehalose, $\mathrm{D}$-xylose, $\mathrm{L}$-alanine, $\mathrm{L}$-arginine, $\mathrm{L}$-asparagine, $\mathrm{L}$ aspartic acid, L-cysteine hydrochloride, L-glutamic acid, L-glutamine, L-histidine, hydroxy-L-proline, L-isoleucine, Lleucine, L-lysine, L-methionine, L-phenylalanine, L-proline, L-serine, L-threonine, L-tryptophan, L-valine, acetic acid, propionic acid, butyric acid, caproic acid, caprylic acid, capric acid, lauric acid, palmitic acid, stearic acid, palmitoleic acid, lignoceric acid, oleic acid, methanol, 
ethanol, 1-propanol, propan-2-ol, 1-butanol, D-lactic acid, oxalic acid, DL-malic acid, tartaric acid, DL- $\beta$ hydroxybutyric acid, adenine, cytosine, guanine, uracil, thymine, xanthine, hypoxanthine, 5-methylcytosine hydrochloride, sodium citrate, sodium pyruvate, sodium succinate, sodium hippurate, creatine, acetamide, Tween 40 , Tween 60 , Tween 80 , Tween 85 , progesterone, oestrogene, stilbestrol, and albumin.

Coding of data. Tests were carried out in duplicate. Most characters were coded as 1 (present), 0 (absent), or 2 (inconsistent), but some were multistate characters (59). When tests recorded the tolerance levels for a substance or the upper and lower limits of growth, the uncoded results were used directly in the analysis. Missing or inapplicable data were coded as -1 (no comparison).

The results were scrutinized before coding, and those tests which gave identical results for all strains examined (e.g., gram-negative or identical results for the Campylobacter strains and the undesignated strains) were omitted from the analysis, as the object was to obtain useful differential tests for these organisms.

Analyses. Cluster and ordination techniques were used. To obtain clusters, single-linkage, complete-linkage, and unweighted-average-linkage methods were used, along with the simple matching $\left(\mathrm{S}_{\mathrm{SM}}\right)$ coefficient, in which both positive and negative matches between character measurements are included (58), and the coefficient of Jaccard ( $S_{\mathrm{J}}$ coefficient), in which only positive matches are considered. Cophenetic correlation coefficients were calculated to assess the goodness of fit of the resulting dendrograms with the calculated similarities. Additional evidence of groupings among the organisms was obtained from an ordination of the similarity coefficients by using the principal coordinate technique (19).

These analyses were carried out by using the DUST computer package (63) on the Queen's University of Belfast computer.

\section{RESULTS}

Most strains gave negative results in the majority of the tests used. The results of the classical biochemical tests, such as sugar reaction and nutritional requirement tests, only accentuated the difference between Vibrio parahaemolyticus and the other strains and were therefore omitted from the computer analyses. Thus, tests of a physiological and inhibitory nature predominated.

Single-linkage analysis. The simplest clustering was obtained by using single-linkage analysis. Using the $\mathrm{S}_{\mathrm{SM}}$ coefficient resulted in four phena at a similarity level of $80 \%$; these phena contained all but 4 of the 150 strains examined. One phenon (44 strains) contained all but three of the Campylobacter strains. Of these three strains, strains 126 and 127 were ungrouped, and strain 93 was incorporated into the largest phenon (98 strains), which contained $98 \%$ of the undesignated strains. "V. percolans" and strain 36 formed a minor phenon linkage at a similarity level of $75 \%$. Both Aquaspirillum strains were members of a separate phenon, which was linked to the phena described above at a similarity level of $70 \%$. V. parahaemolyticus was related to all strains at a similarity level of $60 \%$.

Using positive matches only ( $S_{\mathrm{J}}$ coefficient) gave five phena (similarity level, 80\%), which contained $145(96.7 \%)$ of the strains examined. The undesignated strains were all members of a single phenon, whereas a second phenon contained 41 of the 44 caralase-positive Campylobacter strains. At a similarity level of $75 \%$ all of the catalase-posi- tive Campylobacter strains and the undesignated strains were members of a single large cluster that was separated from the other phena. Campylobacter sputorum (three strains) were members of a single phenon, as were the two Aquaspirillum strains. "V. percolans" and strain 36 also formed a single phenon.

The cophenetic correlation coefficients of these analyses were 0.82 and 0.85 with the $S_{S M}$ and $S_{J}$ coefficients, respectively.

Complete-linkage and unweighted-average-linkage analyses. More compact clusters were obtained by using complete-linkage and unweighted-average-linkage analyses. Very similar arrangements of strains resulted from the use of both of these methods, and therefore only the results of the latter method are presented and discussed below. The simplified dendrogram in Fig. 1 represents the results obtained when average-linkage analysis and the $S_{S M}$ coefficient were used. Where possible, the phena were named after the authentic strains found within them. Encouragingly, the phenon composition was not affected by the exclusion of negative matches $\left(S_{J}\right.$ coefficient). In general, the phena formed at a similarity level of $80 \%$ by using the $S_{S M}$ coefficient were equivalent to those formed at a similarity level of $75 \%$ by using the $S_{J}$ coefficient. In these analyses ( $\mathrm{S}_{\mathrm{SM}}$ and $\mathrm{S}_{\mathrm{J}}$ coefficients), the cophenetic correlation coefficients were 0.88 and 0.87 , respectively.

The test error, which was calculated from the results of tests performed on duplicate strains, was less than $4 \%$ (59).

Three distinct areas (similarity level, 70\%) are recognizable in Fig. 1. Areas A and B contained all of the undesignated strains linked at a similarity level of $80 \%$. These areas were linked to area $C$ (the Campylobacter strains) and to phenon D (Aquaspirillum) at a similiarity level of $60 \%$.

The phena in areas $\mathrm{A}$ and $\mathrm{B}$ contained 84 undesignated strains. These phena did not reflect the origin or the clinical condition of the hosts from which the strains were isolated. The strain composition of each phenon was affected only to a minimal degree by using the $S_{\mathrm{J}}$ coefficient. The phena in area A contained only undesignated strains that were isolated in Northern Ireland.

Phenon B1 contained "V. percolans" and an undesignated strain from outside Northern Ireland.

Phenon B2 consisted of seven Northern Ireland strains and four strains from other laboratories. Closely associated with these strains was another strain isolated outside Northern Ireland; this strain remained ungrouped at the $80 \%$ similarity level.

Phenon C1 (similarity level, 80\%) contained $32 \mathrm{Cam}$ pylobacter fetus strains, including strains from culture collections and laboratory isolates. However, subphena within this phenon did not correspond to the existing C. fetus subspecies. The compositions of the phenon and subphena were not altered when the $S_{\text {J }}$ coefficient was used, but the strain positions within the phenon were altered slightly.

Phenon $\mathrm{C} 2$ consisted of nine strains and had two distinct subphena. These subphena contained strains of Campylobacter coli (subphenon $\mathrm{C} 2 \mathrm{i}$ ) and Campylobacter jejuni (subphenon C2ii) and appeared in analyses when $\mathrm{S}_{\mathrm{SM}}$ and $S_{\mathrm{J}}$ coefficients were used. In the analysis shown, one strain (strain 93) received as $C$. coli was found among the undesignated strains. When only positive matches were used ( $S_{\mathrm{J}}$ coefficient $)$, this strain clustered close to phenon $\mathrm{C} 2$ at a similarity level of $80 \%$.

Phenon C3 contained the three $C$. sputorum reference cultures.

Phenon D contained the two Aquaspirillum strains. 


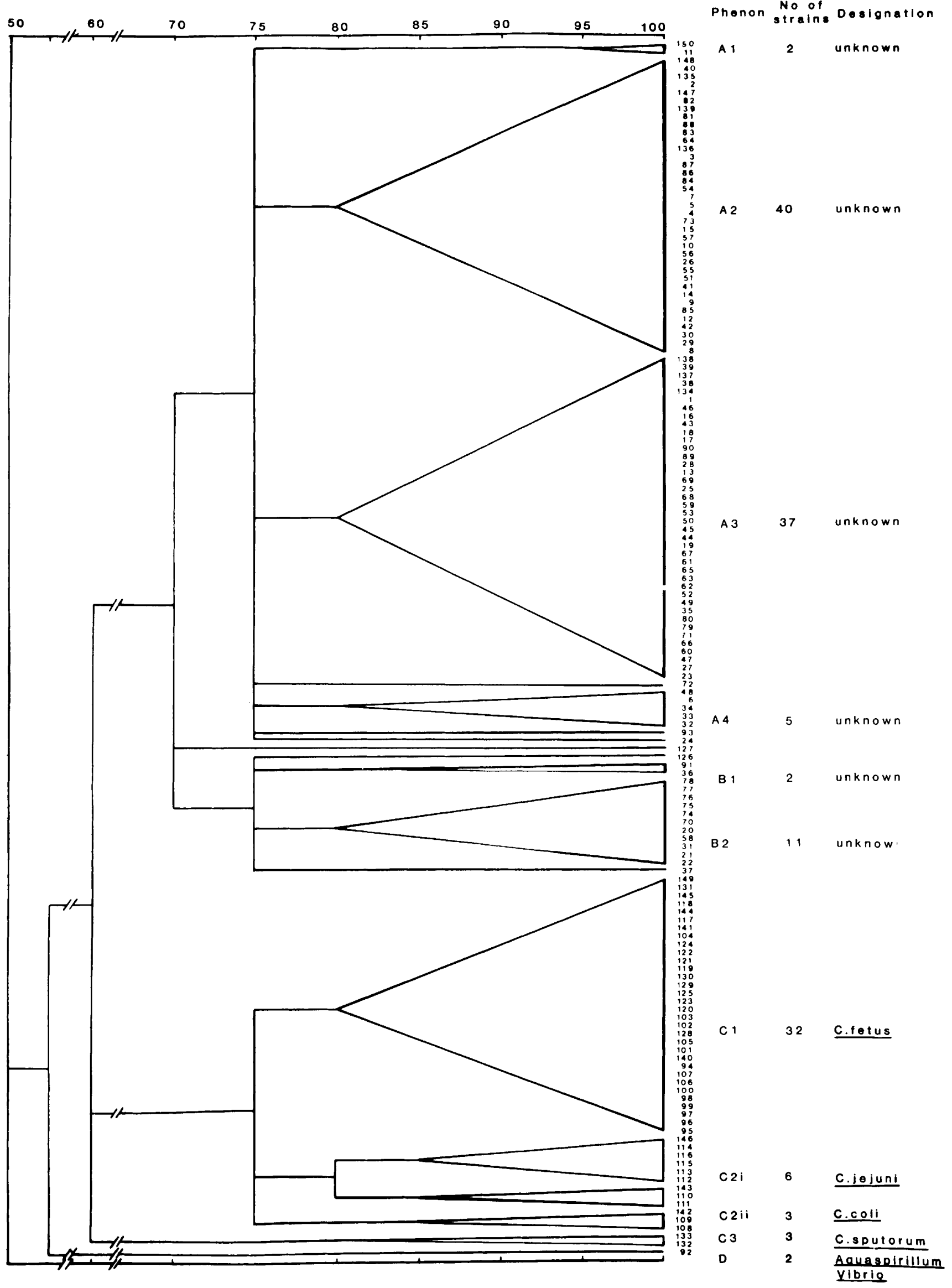

FIG. 1. Simplified dendrogram derived by unweighted-average-linkage analysis, using the $\mathrm{S}_{\mathrm{SM}}$ coefficient. 
TABLE 2. Centrotype strains determined by using averagelinkage analysis

\begin{tabular}{|c|c|c|}
\hline Centrotype strain & Phenon $^{a}$ & Taxon \\
\hline $\mathrm{A} 169 / \mathrm{B}^{\mathrm{T}}$ & A2 & Unassigned \\
\hline $\mathrm{S} 568 / \mathrm{E}$ & A3 & Unassigned \\
\hline B3495/F & A4 & Unassigned \\
\hline LC78351 & B2 & Unassigned \\
\hline 6944 & $\mathrm{C} 1$ & C. fetus \\
\hline $702^{T}$ & $\mathrm{C} 2$ & C. jejuni \\
\hline $53103^{\mathrm{T}}$ & $\mathrm{C} 3$ & C. sputorum subsp. bubulus \\
\hline
\end{tabular}

${ }^{a}$ See Fig. 1.

The relevant centrotype strains (i.e., the strains closest to the centroids) were computed and are shown in Table 2.

Principal coordinate analysis. Principal coordinate analysis was initially carried out by using the test results for only the Campylobacter strains. Figure 2 shows the computation from these data on the first two principal component axes and displays $33.0 \%$ of the total spatial variation. The three distinct groups, which contained all but two of the strains, were named after the authentic strains found within them. This distinct two-dimensional representation of Campylobacter species was achieved regardless of whether negative matches were included or excluded. The principal coordinate analysis for all of the strains tested is shown graphically in Fig. 3 by using two of the first three principal coordinate axes. This plot included $27.5 \%$ of the total variation displayed in the analysis and retained the three distinct species groups displayed previously (Fig. 2). This representation was affected very little by the inclusion of negatively matched results.

Characterization of strains. Each of the analyses separated
$V$. parahaemolyticus from the remainder of the strains. These strains shared many phenotypic features. Strains in areas A, B, and C (Fig. 1) failed to catabolize any of the carbohydrates tested. This was a characteristic of Aquaspirillum polymorphum, although Aquaspirillum itersonii produced acid oxidatively from one carbohydrate. Similarly, most carbon sources at the concentrations used appeared to be of little value for discriminating among the majority of the strains tested. The aquaspirilla differed from the other strains by their oxidative activity in Hugh-Leifson medium, their hydrolysis of tributyrin, esculin, and starch (one strain), and their ability to grow in the presence of potassium cyanide.

Comparison of the strains from areas A, B, and C. All of the strains grew on base medium containing rabbit, cow, horse, sheep, pig, or human blood. Incomplete hemolysis (alpha-hemolysis) was observed with some strains on some of these media, but lack of consistent hemolysis invalidated the use of this character as a differentiating character. The colony appearance on blood agar was variable and was obviously influenced by the surface moisture on the agar medium. In general, the colony appearance of area A and B strains after 24 to $48 \mathrm{~h}$ under reduced oxygen tension was similar to that of area $\mathrm{C}$ strains. After continued incubation, the colonies of area $\mathrm{C}$ strains usually became larger, coarser, and more opaque.

For the purpose of objective differentiation among strains from areas $\mathrm{A}, \mathrm{B}$, and $\mathrm{C}$, no distinctive pigmentation was observed on blood agar or King media $\mathrm{A}$ and $\mathrm{B}$. Colonies on the former medium ranged from off-white to pale yellow.

All strains were gram-negative, motile rods that exhibited varying degrees of cell curvature and after prolonged culture could become elongated, helical forms of different lengths.

For area $\mathrm{A}, \mathrm{B}$, and $\mathrm{C}$ strains the following tests were

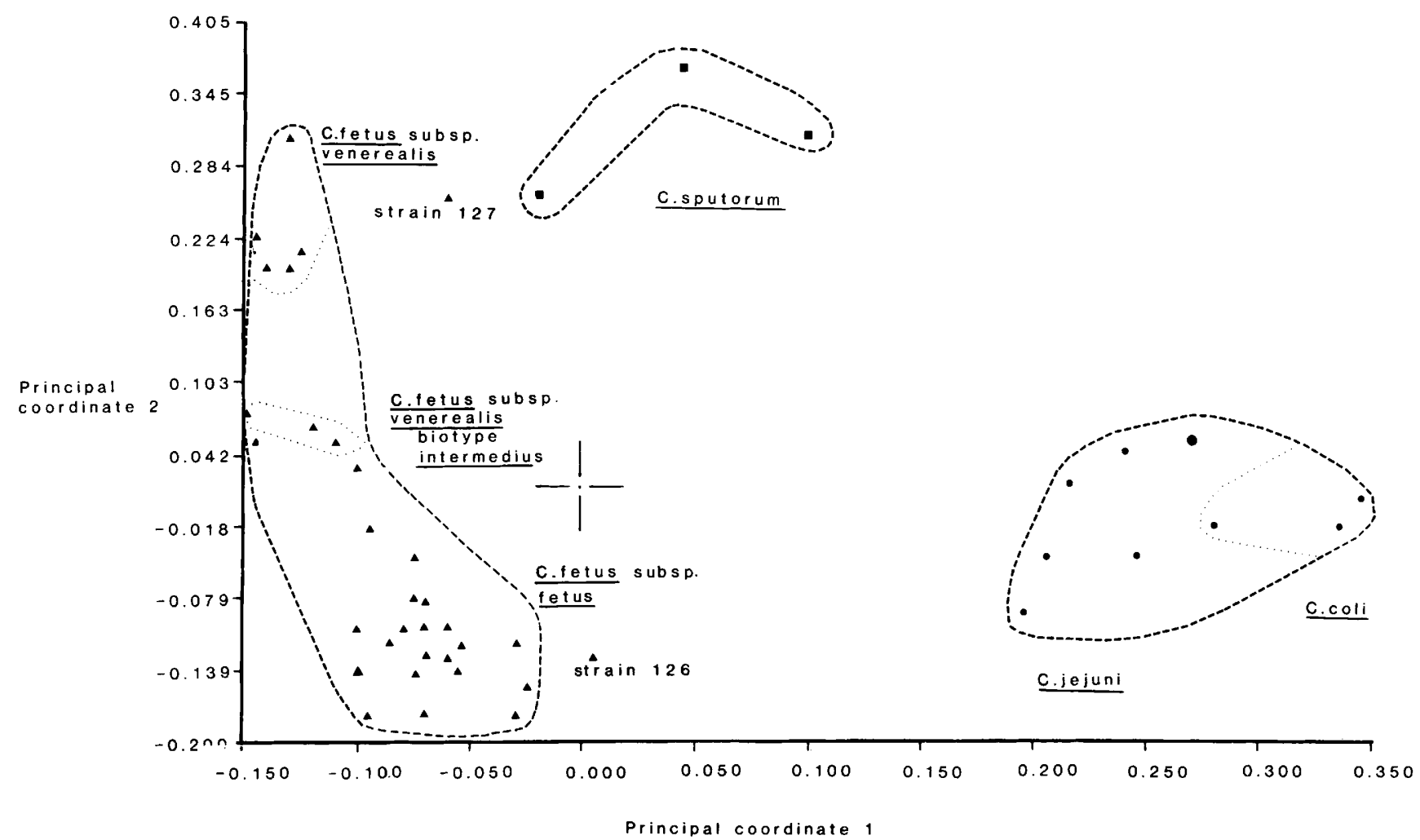

FIG. 2. Ordination plot from the principal coordinate analysis of named Campylobacter strains only. 


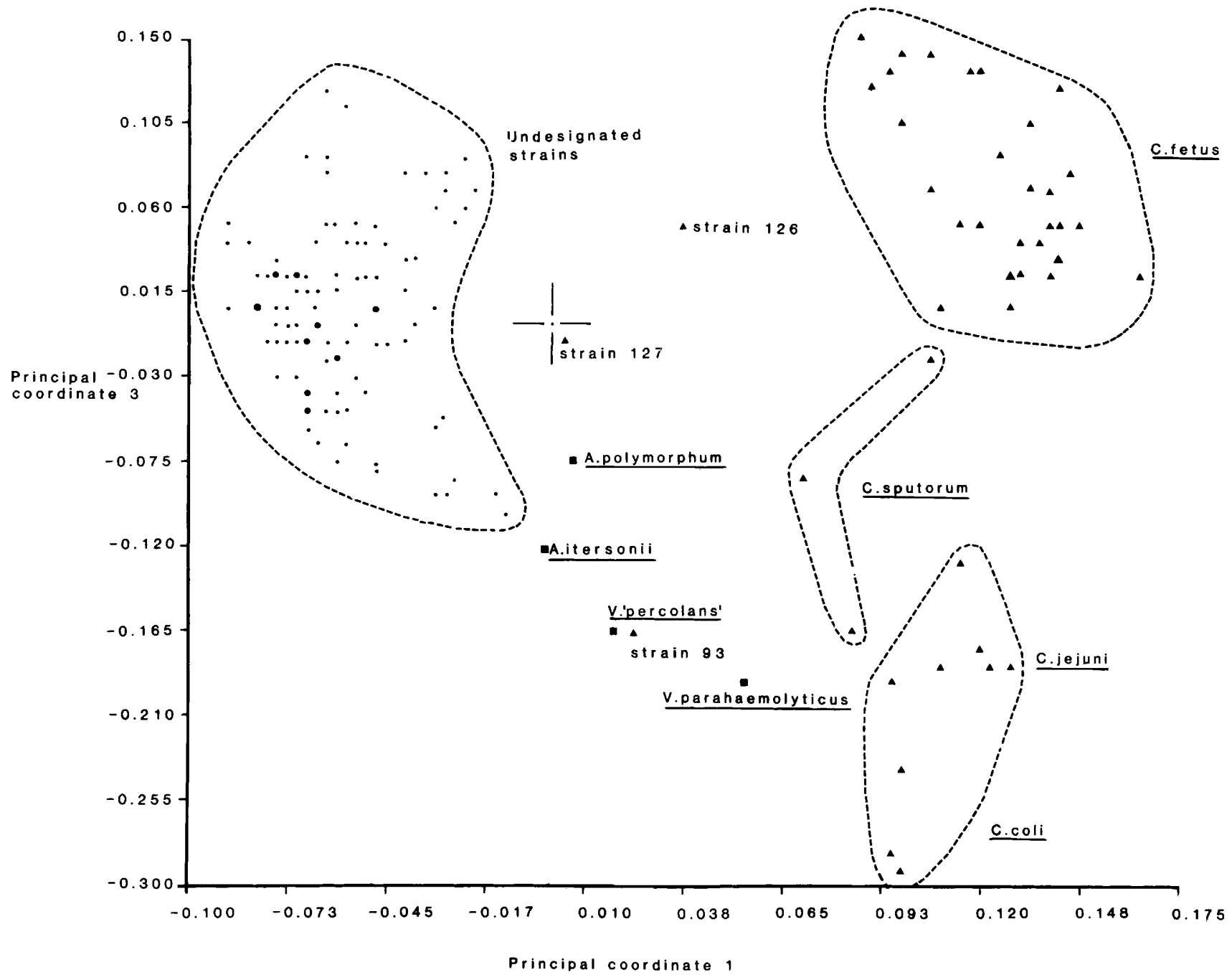

FIG. 3. Ordination plot from the principal coordinate analysis of all of the strains examined.

positive: oxidase activity ( $100 \%$ of the strains); nitrate reduction $(98.6 \%)$; nitrite reduction $(95.2 \%)$; growth in air containing $10 \% \mathrm{CO}_{2}(90.0 \%)$ or under anaerobic conditions $(85.9 \%)$; growth in the presence of $1 \% \mathrm{NaCl}, 4.0 \%$ glucose, $0.1 \%$ glycine, or vibriostatic agent 0/129 (100\%).

The following tests were negative for area $\mathrm{A}, \mathrm{B}$, and $\mathrm{C}$ strains: methyl red (100\% of the strains); Voges-Proskauer $(100 \%)$; production of indole, ornithine, lysine, and arginine decarboxylases, urease, ribonuclease, and deoxyribonuclease $(97.9 \%)$; utilization of citrate, malonate, and gluconate $(100 \%)$; liquefaction of serum and gelatin $(100 \%)$; hydrolysis of casein $(100 \%)$, starch $(100 \%)$, hippurate $(100 \%)$, tributyrin $(99 \%)$, and esculin $(100 \%)$; growth in the presence of $\mathrm{KCN}$ $(98.6 \%)$ and on deoxycholate agar $(100 \%)$; and catabolism of a range of carbohydrates $(100 \%)$. The strains decolorized litmus milk ( $92.5 \%$ of the strains), were inert or produced no reaction in Crossley milk, and produced an alkaline reaction in Hugh-Leifson medium.

Uniformly and consistently, all of the area A and B strains grew in atmospheric oxygen on solid media. In contrast, the area C strains consistently failed to grow in this atmosphere.

Relatively few characters could be used successfully to distinguish the area $\mathrm{A}, \mathrm{B}$, and $\mathrm{C}$ strains from one another. These characters are shown in Table 3.
Comparison of phena. Although most of the phenotypic characters examined were common to the majority of strains, many were not uniformly present in all of the strains in any one phenon. Few distinctive characters were recognized as separating the phena produced at any particular level. The phena differed more in the degree to which strains could tolerate a particular substance than in distinct differences in the substances tolerated. The characters that were

TABLE 3. Characters which have the most value for distinguishing among area $\mathrm{A}, \mathrm{B}$, and $\mathrm{C}$ strains

\begin{tabular}{cccccc}
\hline Area & $\begin{array}{c}\text { No. of } \\
\text { strains }\end{array}$ & Growth in air & $\begin{array}{c}\text { Growth at } \\
15^{\circ} \mathrm{C}^{a}\end{array}$ & $\begin{array}{c}\text { Growth in the } \\
\text { presence of } \\
\mathrm{NaCl}(2 \%)^{a}\end{array}$ & $\begin{array}{c}\text { Growth in the } \\
\text { presence of } \\
\text { carbenicillin } \\
(64 \mu \mathrm{g} / \mathrm{ml})^{a}\end{array}$ \\
\hline $\mathrm{A}$ & 88 & $+(100)^{b}$ & $+(100)$ & $+(86.2)$ & $+(93.1)$ \\
$\mathrm{B}$ & 15 & $+(100)$ & $+(100)$ & $+(100)$ & $+(87.6)$ \\
$\mathrm{C}$ & 44 & $-(0)$ & $-(0)$ & $-(0)$ & $-(2.3)$ \\
\hline
\end{tabular}

"Growth under reduced oxygen tension $\left(85 \% \mathrm{~N}_{2}, 10 \% \mathrm{CO}_{2}, 5 \% \mathrm{O}_{2}\right)$

${ }^{b}+$, More than $85 \%$ of the strains were positive; -, less than $15 \%$ of the strains were positive. The values in parentheses are the percentages of positive strains. 


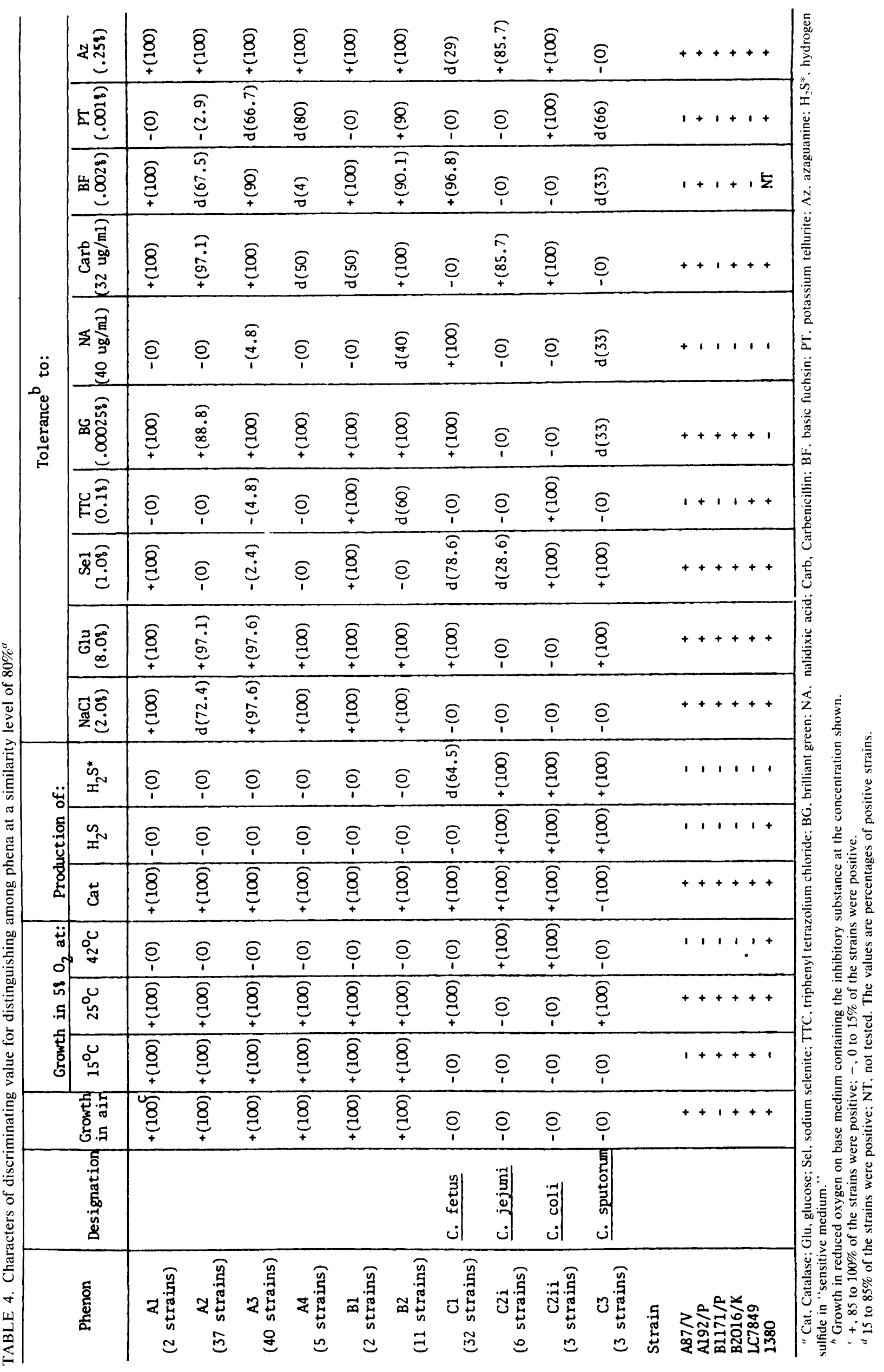


useful for assigning strains to the phena at a similarity level of $80 \%$ are shown in Table 4 .

\section{DISCUSSION}

The assignment of the strains studied to the same general arrangement by using several analytic methods strengthened the taxonomic validity of the groupings produced. The cophenetic correlation coefficients produced for the singlelinkage and average-linkage analyses indicated a satisfactory correlation between the original similarity values and those of the respective phena from each analysis.

From the dendrogram (Fig. 1), it could be suggested that generic status should be attributed to each of the areas shown, as the current genus Campylobacter was clearly recognizable as area $\mathrm{C}$. However, consideration must also be given to the distinct lack of biochemical activities common to all of the strains in the three areas and to the generic unison that can be inferred (4) from the deoxyribonucleic acid base ratios of representative strains shown in Table 5 . Therefore, it is more realistic and practical to suggest that the undesignated strains be considered a new and distinct group, which is more distantly related to any of the existing Campylobacter species than these species are to each other. In the simplest of the analyses (single-linkage analysis), the undesignated strains clustered significantly more closely to the named Campylobacter strains than to the Aquaspirillum strains $\left(\mathrm{S}_{\mathrm{SM}}\right.$ coefficient), and when only positive matches were used ( $S_{\text {J }}$ coefficient $)$, the catalase-positive Campylobacter and undesignated strains formed a single phenon (similarity level, 75\%). The new group includes some recently isolated strains; some of these strains had been held in storage, and others had had prolonged laboratory passage. The strains also originated from a variety of sources, and this new group therefore complies with the concept of a species (18).

$A$. polymorphum and $A$. itersonii were included in this study because they are among the smallest spirilla (comparable in size to Campylobacter strains) and not because they are representative spirilla, which include bacteria that are morphologically, physiologically, and biochemically quite varied $(24,32)$. The distinction of the Aquaspirillum strains from the named and undesignated Campylobacter strains is clearly illustrated in the cluster diagram (Fig. 3).

The Campylobacter-like organism "V. percolans" (47) was recovered in area B (Fig. 1), yet it possessed the following conspicuous characters that are absent in Campylobacter strains: hydrolysis of tributyrin and casein and tolerance to $\mathrm{KCN}$. These characteristics were obviously outweighed by the large number of phenotypic characters shared with Campylobacter. The difference between " $V$. percolans" and Campylobacter strains, which has been illustrated previously (43), was again more realistically demonstrated in the cluster diagram (Fig. 3).

The phena (similarity level of $80 \%$ with the $\mathrm{S}_{\mathrm{SM}}$ coefficient; similarity level of $75 \%$ with the $S_{J}$ coefficient) identified in this study have valid taxonomic significance, as similarity levels of 75 and $80 \%$ have been previously suggested as good criteria for phenetic species $(36,59)$. Both phenetic and cluster presentations (Fig. 1 through 3) contained the reference and type strains appropriately grouped and largely supported the species differentiation within the genus Campylobacter described by Véron and Chatelain (62). However, the strains included as authentic members of C. fetus subspecies were distinguished as such only in the principal coordinate analysis and were not separated into discrete subphena in the single-linked analysis. At the level
TABLE 5. Deoxyribonucleic acid base compositions of strains

\begin{tabular}{|c|c|c|c|c|}
\hline \multirow{2}{*}{ Taxon } & \multirow{2}{*}{ Phenon $^{a}$} & \multirow{2}{*}{ Strain } & \multicolumn{2}{|c|}{$\mathrm{G}+\mathrm{C}$ content $(\mathrm{mol} \%)$} \\
\hline & & & Range $^{b}$ & Mean $^{c}$ \\
\hline C. fetus & $\mathrm{C} 1$ & & $33.0-35.5$ & \\
\hline C. coli or C. jejuni & $\mathrm{C} 2$ & & $29.0-34.0$ & \\
\hline C. sputorum & $\mathrm{C} 3$ & & $29.0-31.0$ & \\
\hline "V. percolans" & B1 & & $58.9-65.0$ & \\
\hline Aquaspirillum & $\mathrm{D}$ & & $50.0-65.0$ & \\
\hline \multirow[t]{4}{*}{ V. parahaemolyticus } & & & $42.0-45.0$ & \\
\hline & & A175/P & & $29.6(0.5)^{c}$ \\
\hline & & B1019 & & $30.1(1.2)$ \\
\hline & & $\mathrm{A} 175 / \mathrm{K}$ & & $30.8(0.8)$ \\
\hline \multirow[t]{5}{*}{ Unassigned } & A2 & $\mathrm{A} 169 / \mathrm{B}$ & & $31.5(0.2)$ \\
\hline & & $\mathrm{A} 171 / \mathrm{E}$ & & $32.0(1.3)$ \\
\hline & & B1904/E & & $33.9(0.3)$ \\
\hline & & B1049/P & & $29.5(0.2)$ \\
\hline & & $\mathrm{A} 102 / \mathrm{Pt}$ & & $30.3(0.7)$ \\
\hline \multirow[t]{2}{*}{ Unassigned } & $\mathrm{A} 3$ & S568/E & & $31.8(1.1)$ \\
\hline & & S613A/E & & $29.9(0.2)$ \\
\hline Unassigned & B2 & $\mathrm{B} 2211 / \mathrm{Sc}$ & & $29.6(0.6)$ \\
\hline
\end{tabular}

${ }^{a}$ See Fig. 1.

${ }^{b}$ The base ratios of the organisms are generally accepted to be within the ranges shown $(5,32,38,46,51,55,62)$.

c See reference 43 .

${ }^{d}$ The values in parentheses are standard errors.

at which $C$. fetus and C. sputorum are recognizable (Fig. 1), $C$. jejuni and $C$. coli strains appeared together in one phenon, yet they were separable components of this phenon. Studies of the deoxyribonucleic acids of Campylobacter strains have shown that $C$. jejuni and $C$. coli are more similar to each other than to $C$. fetus when guanine-plus-cytosine $(\mathrm{G}+\mathrm{C})$ contents and genome sizes are used but are distinct and separate species when deoxyribonucleic acid hybridization techniques are used $(35,46)$.

Although for practical purposes the undesignated Campylobacter strains (areas A and B) were considered members of one group (Fig. 3), they were heterogeneous. Area A contained only strains that were isolated in Northern Ireland, whereas area B contained cultures from geographical areas outside Northern Ireland. At the similarity level (70\%) which revealed the previously described Campylobacter. species, subgroups of strains were evident in areas A and B. None of these subgroups could be correlated with a particular host or with the origin or clinical state of the host, and none included a predominance of recently isolated strains over stored strains or laboratory-passaged cultures. The true extent of the heterogeneity of the undesignated aerotolerant strains and their precise relationship to the other Campylobacter species can only be determined by deoxyribonucleic acid hybridization studies. The mean $\mathrm{G}+\mathrm{C}$ contents of the 11 strains examined was $31 \pm 1 \mathrm{~mol} \%$, a value more similar to the $\mathrm{G}+\mathrm{C}$ content of $C$. sputorum than to that of C. fetus, C. jejuni, or C. coli.

The centrotype strains produced for phena $\mathrm{C} 1, \mathrm{C} 2$, and $\mathrm{C} 3$ (Table 2) are reference cultures held in collections; strain 702 is a type strain. Although centrotype strain 6944 is not the type strain of $C$. fetus, its closest neighbor in the analysis was strain 5396, which is the type strain of C. fetus. Strain A169/B is regarded as the type strain of the aerotolerant undesignated strains.

In taxonomic studies it is desirable to use uniform cultural conditions and a single base medium. Unfortunately, consistent and healthy growth of all of the strains examined could not be sustained at one temperature, and it was also 
necessary to maintain the strains in two different media before testing. These different cultural procedures appeared to have little effect on the groups produced in the analyses, as three undesignated strains maintained at $37^{\circ} \mathrm{C}$ and examined by using tests carried out at $37^{\circ} \mathrm{C}$ clustered with the remaining undesignated strains, which were maintained and tested at $30^{\circ} \mathrm{C}$.

Subjective characters, such as pigmentation, were of little value for distinguishing among the phena or clusters. However, morphology was sometimes distinctive. The colonies of $C$. coli and $C$. jejuni strains were usually larger than the colonies of either $C$. fetus or the undesignated strains, and the former organisms swarmed readily on moist agar. The colony sizes of $C$. fetus and the undesignated strains after 24 to $48 \mathrm{~h}$ of incubation were similar, but after continued incubation $C$. fetus colonies became larger, coarser, and more opaque and usually could be distinguished from colonies of the undesignated strains. Microscopically, the cells of $C$. coli and $C$. jejuni were characteristically smaller and more tightly curved than the cells of the other strains; the cells of $C$. coli and $C$. jejuni had a tendency to become coccoid, especially in older cultures. The cells of $C$. fetus and the undesignated strains were not so visibly distinct, and the observed similarities in cell sizes make the use of microscopic appearance for identification fraught with danger. Cell morphology may in fact vary with changes in cultural conditions.

Although at least four possible species could be clearly recognized, the distinguishing characters of these taxa were not so obvious. Strains differed more in the degree to which a compound was tolerated than in the compounds tolerated. This study illustrates the following problem often encountered in bacterial taxonomy: separation of bacteria may not be by sharp divisions, but by slight and subtle differences in characters, so that the strains resemble a spectrum. Interestingly, of the characters examined, those of possible discriminatory value (Tables 3 and 4) were quite similar to the characters previously recognized by other workers as valuable for Campylobacter species differentiation (1, 2, 52, $53,55,62)$. In this study we found that all of the Campylobacter strains tested were unable to hydrolyze hippurate; however, the test method used was different from that recently recommended (21). Use of this latter method confirmed that the undesignated strains are not able to hydrolyze hippurate (unpublished data).

Table 3 illustrates the limited characters by which the aerotolerant strains can be recognized. By definition, Campylobacter strains are microaerophilic; they respire yet are usually inhibited by atmospheric oxygen. The optimum oxygen concentration for Campylobacter growth has been reported to be $6 \%(27,49)$, but the aerotolerance of strains can be artificially enhanced on supplemented media $(3,17$, 30). Therefore, the aerotolerant undesignated strains could represent one end of a spectrum of natural oxygen tolerance among Campylobacter strains; $C$. sputorum represents the other end. This oxygen spectrum concept is supported by the degree of inhibition exhibited to nitroimidazole drugs. $C$. sputorum strains were most susceptible, and the undesignated strains were most resistant. The majority of the area A, B, and C strains (Fig. 1) were resistant to metronidazole at concentrations up to $4 \mu \mathrm{g} / \mathrm{ml}$; however, at a metronidazole concentration of $64 \mu \mathrm{g} / \mathrm{ml}$ all of the strains of the previously described Campylobacter species were inhibited, whereas the undesignated strains were less susceptible (area A strains, $57.5 \%$ inhibited; area B strains, $78.9 \%$ inhibited). It is of interest that a range of susceptibility to nitroimidazole drugs was observed with the undesignated strains; the fact that strains isolated from pigs exhibited greater resistance may have been due to the greater contact of pigs with nitroimidazoles.

Differences in temperature tolerance have proved to be useful for Campylobacter differentiation (12, 52-54, 62). In this study all of the area A, B, and C strains (Fig. 1) grew at $37^{\circ} \mathrm{C}$, with $50 \%$ of the undesignated area A strains at growing temperatures up to $40^{\circ} \mathrm{C}$. However, the lower limits of growth were more useful for differentiation. Area A and B strains consistently grew at much lower temperatures than area $C$ strains; $43.2 \%$ of the area $A$ strains and $21 \%$ of the area $\mathrm{B}$ strains grew at temperatures as low as $5^{\circ} \mathrm{C}$. All area $\mathrm{A}$ and area $B$ strains grew at $15^{\circ} \mathrm{C}$, whereas none of area $\mathrm{C}$ strains grew at this temperature. This provided a unique differential character. This psychrophilic nature of the undesignated strains could place them at one end of a temperature spectrum for Campylobacter; at the opposite end of this spectrum are the thermophilic strains.

Differences in sodium chloride tolerance have also been used to group Campylobacter strains $(13,20,25,37)$. Our results indicate that the majority of the undesignated strains are inhibited by $3.0 \% \mathrm{NaCl}$ and that previously described catalase-positive Campylobacter strains are inhibited by $2 \%$ $\mathrm{NaCl}$. Sensitivity of the undesignated strains to levels of salt above $2 \%$ was not consistent for all strains in either of area A or area B. Only a minority $(17 \%)$ of the undesignated strains grew at salt concentrations of $3.5 \%$ or above; these strains are perhaps similar to the aerobic vibrios described by other workers $(25,41)$. Tolerance to $3.5 \% \mathrm{NaCl}$ has been cited as a characteristic which distinguishes between pathogenic and saprophytic Campylobacter strains $(25,41)$; when this criterion was used, the majority of the undesignated strains examined could be described as potentially pathogenic.

Tolerance to the antibiotics examined was similarly not uniform for all of the strains in each of the areas. Campylobacter strains (area C) were markedly more resistant to nalidixic acid and to polymyxin than were area $\mathrm{A}$ and B strains, but were generally more susceptible to carbenicillin, ampicillin, the nitroimidazoles, and chloramphenicol. Susceptibility to penicillin, streptomycin, and kanamycin appeared to be similar for all strains. Only carbenicillin susceptibility $(64 \mu \mathrm{g} / \mathrm{ml})$ could be used as a distinguishing character for the undesignated aerotolerant strains.

Inhibition by most of the other substances examined was not held in common by all strains in any of the groups observed. The majority $(93.2 \%)$ of the strains examined tolerated media with initial $\mathrm{pH}$ values of 6.8 to 8.0. However, greater proportions of area A and B strains (35.7 and $36.8 \%$ ) tolerated $\mathrm{pH} 9.5$ than area $\mathrm{C}$ strains $(16.7 \%)$. No area $\mathrm{C}$ strains and few area $\mathrm{A}$ and $\mathrm{B}$ strains $(8.0$ and $10.5 \%$, respectively) grew on media with initial $\mathrm{pH}$ values above 9.5 . None of the area A strains survived on medium with an initial $\mathrm{pH}$ of 5.5 , whereas area $\mathrm{B}$ and $\mathrm{C}$ strains did survive ( 58 and $88 \%$, respectively). None of the strains examined grew on media with an initial $\mathrm{pH}$ of 5.0.

It was not totally unexpected to find that the majority of the Northern Ireland strains clustered closely together and separate from the strains isolated in other geographical areas. Most of the isolates examined were from animals, and, as antibiotic susceptibility may be influenced by the antibiotic usage in different localities, the clustering of strains could reflect to some extent the geographical origins.

Unexpectedly, strain 93 (C. fetus subsp. jejuni or Vibrio coli) and strains 126 and 127 (C. fetus) were excluded from 
the phena and clusters that contained the appropriate reference cultures (Fig. 1 and 3). Under test conditions, strain 93 grew at both 42 and $25^{\circ} \mathrm{C}$, failed to produce hydrogen sulfide, and grew aerobically; this strain was probably misidentified originally. Strains 126 and 127 , although correctly identified as $C$. fetus (62), had characteristics different from those of the strains in the $C$. fetus cluster. Both of these strains failed to reduce nitrate, a character which is found positive for all of the C. fetus strains tested, and both strains grew in atmospheric oxygen. In addition, strain 126 grew at temperatures below $15^{\circ} \mathrm{C}$ and tolerated $4 \% \mathrm{NaCl}$. The recognition of these rogue strains highlights the potential hazard of relying on the small number of discrete phenotypic characters described above and a predominance of inhibitory-type tests. The distinguishing pattern of correlating properties should be large enough to permit variation of a few properties by a strain without excluding the strain from the species (18). This problem has been previously encountered with some Campylobacter strains, as identification difficulties have been described by other workers $(12,56,62)$.

Table 4 shows those characters that are common to the majority of the strains in each of the phena produced by group average-linkage analysis (Fig. 1). This table shows that the phena differ by relatively few phenotypic characters. However, these characters permitted separation of the named Campylobacter strains included in the study into recognized species, even though only a few strains of some of these species were included. No practical significance could be established for the subdivision of the undesignated aerotolerant strains into the phena shown, and separation may only be of purely taxonomic interest, as some phena differed by as little as one or two phenotypic characters.

Topical interest in enteric Campylobacter strains has highlighted the taxonomic diversity of the intestinal strains $(52,53)$, and subsequent characterization studies have identified several new and potentially new species for inclusion within the expanding genus Campylobacter $(2,11,16,33,39$, 60,61 ).

This study showed the phenotypic relationship of novel aerotolerant Campylobacter strains to at least some strains of the previously established species. The aerotolerant strains clearly appear to be unrecognized species within the genus, and Campylobacter cryaerophila is proposed as a name for this species.

Description of Campylobacter cryaerophila sp. nov. Campylobacter cryaerophila (cry.ae.ro.philá. Gr. adj. cry cold; Gr. n. aero air; L. adj. phila fond of; cryaerophila fond of cold and air) cells are gram-negative nonsporeforming rods $(0.4 \mu \mathrm{m}$ wide by $1.8 \mu \mathrm{m}$ long); unusually long cells $(>20$ $\mu \mathrm{m}$ ) have been observed. Cells are usually curved, S shaped, or helical. Darting motility; single polar flagella (amphitricate). Growth occurs at $30^{\circ} \mathrm{C}$, and colonies grown under reduced oxygen tension for 48 to $72 \mathrm{~h}$ are small $(1 \mathrm{~mm}$ in diameter), smooth, and convex with entire edges. Colonies may become flattened and irregular and may vary in size. Strains in subculture grow in air, in air containing $10 \% \mathrm{CO}_{2}$, and anaerobically. Some strains grow between 5 and $40^{\circ} \mathrm{C}$, but all strains grow at $15^{\circ} \mathrm{C}$. The strains are positive for catalase and oxidase activities and reduce nitrate $(98.6 \%$ of the strains) and nitrite (85.9\%). The strains are tolerant to $2 \%$ $\mathrm{NaCl}, 4 \%$ glucose, $0.1 \%$ glycine, and pteridine vibriostatic compound $0 / 129$. The strains do not grow in medium containing $1.0 \%$ glycine and $1 \mathrm{mg}$ of 2,3,5-triphenyl tetrazolium chloride per ml, and sodium selenite is not reduced. $\mathrm{No}_{2} \mathrm{~S}$ is produced in triple sugar iron medium or medium containing cystine. The strains produce alkaline reactions in Hugh-
Leifson medium. All strains are negative in methyl red and Voges-Proskauer tests and do not produce indole, ornithine, lysine, and arginine decorboxylases, urease, ribonuclease, or deoxyribonuclease ( $97.9 \%$ of the strains). The strains do not utilize citrate, malonate, or gluconate, do not liquify serum or gelatin, and do not hydrolyze casein, starch, hippurate, tributyrin, or esculin. Growth does not occur in $\mathrm{KCN}$ or on deoxycholate agar, and all strains fail to catabolize carbohydrates. The strains are susceptible to nalidixic acid $(40 \mu \mathrm{g} / \mathrm{ml})$ and resistant to carbenicillin $(64 \mu \mathrm{g} / \mathrm{ml})$.

Strains have been isolated from reproductive tracts and aborted fetuses of several species of farm animals, from animal feces, and from milk of mastitis cows.

The mean $\mathrm{G}+\mathrm{C}$ content is $31 \pm 1 \mathrm{~mol} \%$.

Strain A169/B $(=02766)$ is the type strain of $C$. cryaerophila and has been deposited in the National Collection of Type Cultures as strain NCTC 11885. This strain conforms to the description given above for the species with respect to morphology and growth characteristics. No growth occurs below $5^{\circ} \mathrm{C}$ or above $37^{\circ} \mathrm{C}$; the optimum growth temperature is $30^{\circ} \mathrm{C}$. Strain $\mathrm{A} 169 / \mathrm{B}^{\mathrm{T}}$ ( $\mathrm{T}=$ type strain) is catalase and oxidase positive and reduces nitrate and nitrite. Methyl red and Voges-Proskauer tests are negative, and indole is not produced; ornithine, lysine, and arginine decarboxylases, urease, ribonuclease, and deoxyribonuclease are not produced. Citrate, malonate, and gluconate are not utilized; serum and gelatin are not liquified, and casein, starch, hippurate, tributyrin, and esculin are not hydrolyzed. No acid is produced from carbohydrates. No reaction is produced in litmus milk or Crossley milk, and an alkaline reaction occurs in Hugh-Leifson medium.

Growth occurs on medium containing $8 \%$ glucose and pteridine vibriostatic compound $0 / 129$. No growth occurs on medium containing $>2 \% \mathrm{NaCl}, 1.0 \%$ glycine, or $1 \mathrm{mg}$ of 2,3,5-triphenyl tetrazolium chloride per $\mathrm{ml}$. Sodium selenite is not reduced, and no $\mathrm{H}_{2} \mathrm{~S}$ is produced in triple sugar iron medium or medium supplemented with cystine. No growth occurs on McConkey or desoxycholate agar.

Antibiotic susceptibility: resistant to ampicillin $(18 \mu \mathrm{g} / \mathrm{ml})$, carbenicillin $(64 \mu \mathrm{g} / \mathrm{ml})$, chloramphenicol $(4 \mu \mathrm{g} / \mathrm{ml})$, dimetridazole $(1 \mu \mathrm{g} / \mathrm{ml})$, kanamycin $(2 \mu \mathrm{g} / \mathrm{ml})$, metronidazole $(8 \mu \mathrm{g} / \mathrm{ml})$, nalidixic acid $(5 \mu \mathrm{g} / \mathrm{ml})$, penicillin $\mathrm{G}(1 \mathrm{IU} / \mathrm{ml})$, and polymyxin B $(2 \mu \mathrm{g} / \mathrm{ml})$; susceptible to streptomycin $(12$ $\mu \mathrm{g} / \mathrm{ml})$.

The $\mathrm{G}+\mathrm{C}$ content of the type strain is $31.5 \mathrm{~mol} \%$.

Strain A169/B ${ }^{\mathrm{T}}$ was isolated from an aborted bovine fetus.

\section{ACKNOWLEDGMENTS}

We thank the following individuals for providing strains used in this study: B. D. Firehammer, Montana State University, Bozeman; R. Higgins, University of Montreal, Montreal, Canada; T. A. Little, Central Veterinary Laboratories, Weybridge, England; E. Mitscherlich, Tierärztliches Institut, Göttingen, Göttingen, Federal Republic of Germany; and E. Nichol, Edinburgh, Scotland.

\section{LITERATURE CITED}

1. Bates, P. G. J. 1981. Isolation and identification of campylobacters. Medium 14:8-17.

2. Benjamin, J., S. Leaper, R. J. Owen, and M. B. Skirrow. 1983. Description of Campylobacter laridis, a new species comprising the nalidixic acid resistant thermophilic Campylobacter (NARTC) group. Curr. Microbiol. 8:231-238.

3. Border, M. M., B. D. Firehammer, and L. L. Myers. 1974. Tube culture for viable counts of Campylobacter foetus (Vibrio fetus). Appl. Microbiol. 28:730-732.

4. Bradley, S. G. 1980. DNA re-association and base composition, p. 11-26. In M. Goodfellow and R. G. Board (ed.), 
Microbiological classification and identification. Academic Press, Inc. (London), Ltd., London.

5. Charlier, G., P. Dekeyser, A. Florent, R. Strobbe, and L. Deley. 1974. DNA base composition and biochemical characters of Campylobacter strains. Antonie van Leeuwenhok J. Microbiol. Serol. 40:145-151.

6. Christensen, W. E. 1946. Urea decomposition as a means of differentiating Proteus and Paracolon cultures from each other and from Salmonella and Shigella. J. Bacteriol. 52:461-466.

7. Cowan, S. T. 1974. Manual for the identification of medical bacteria, 2nd ed. Cambridge University Press, Cambridge.

8. Ellis, W. A., S. D. Neill, J. J. O'Brien, H. W. Ferguson, and J. Hanna. 1977. Isolation of Spirillum/Vibrio-like organisms from bovine foetuses. Vet. Rec. 100:451-452.

9. Ellis, W. A., S. D. Neill, J. J. O'Brien, and J. Hanna. 1978. Isolation of Spirillum-like organisms from pig foetuses. Vet. Rec. 102:106.

10. Falkow, S. 1958. Activity of lysine decarboxylase as an aid in the identification of Salmonella and shigellae. Am. J. Clin. Pathol. 29:598-600.

11. Fennell, C. L., P. A. Totten, T. C. Quinn, K. K. Holmes, and W. E. Stamm. 1983. Characterisation of human campylobacterlike organisms, p. 47-48. In A. D. Pearson, M. B. Skirrow, B. Rowe, J. R. Davies, and D. M. Jones (ed.), Campylobacter II. Public Health Laboratory Service, London.

12. Firehammer, B. D., and R. L. Berg. 1965. The use of temperature tolerance in the identification of Vibrio fetus. Am. J. Vet, Res. 26:995-997.

13. Fletcher, R. D., and W. N. Plastridge. 1963. Clinically defined medium for some microaerophilic vibrios. J. Bacteriol. 85:992-995.

14. Florent, A. 1953. Isolement d'un vibrion satrophte du sperme du taureau et du vagin de la vache (Vibrio bubulus). C. R. Soc. Biol. 147:2066-2069.

15. Gagnon, M., W. N. Hunting, and W. B. Esselen. 1959. New method for catalase determination. Anal. Chem. 31:144-146.

16. Gebhart, C. J,, G. E. Ward, K. Chang, and H. J. Kurtz. 1983. Campylobacter hyointestinalis (new species) isolated from swine with lesions of proliferative ileitis. Am. J. Vet. Res. 44:361-367.

17. George, H. A., P. S. Hoffman, R. M. Smibert, and N. R. Krieg. 1978. Improved media for growth and aerotolerance of Campylobacter fetus. J. Clin. Microbiol. 8:36-41.

18. Gordon, R. E. 1978. A species definition. Int. J. Syst. Bacteriol. 28:605-607.

19. Gower, J. C. 1966. Some distance properties of latent root and vector methods used in multivariate analysis. Biometrika 53:325-338.

20. Hanninen, M. L. 1981. The effect of $\mathrm{NaCl}$ on Campylobacter jejuni/coli. Acta Vet. Scand. 22:578-588.

21. Harvey, S. N. 1980. Hippurate hydrolysis by Campylobacter fetus. J. Clin. Microbiol. 11:435-437.

22. Holdeman, L. V., and W. E. C. Moore (ed.). 1972. Anaerobe laboratory manual, 2nd ed. Virginia Polytechnic Institute and State University, Blacksburg.

23. Hugh, R., and E. Leifson. 1953. The taxonomic significance of fermentative vs oxidative metabolism of carbohydrates by various gram-negative bacteria. J. Bacteriol. 66:24-26.

24. Hylemon, P. D., J. S. Wells, N. R. Krieg, and H. W. Jannasch. 1973. The genus Spirillium: a taxonomic study. Int. J. Syst. Bacteriol. 23:340-380.

25. Jakovljevic, D. 1973. Salt tolerance and the classification of vibrios isolated from cattle. Aust. Vet. J. 49:546-547.

26. Jones, F. S., M. Orcutt, and R. B. Little. 1931. Vibrios (Vibrio jejuni n.sp.) associated with intestinal disorders of cows and calves. J. Exp. Med. 53:853-863.

27. Kiggins, R. M., and W. N. Plastridge. 1958. Some metabolic activities of Vibrio fetus of bovine origin. J. Bacteriol. 75:205-208.

28. King, E. O. 1962. The laboratory recognition of Vibrio fetus and a closely related vibrio isolated from cases of human vibriosis. Ann. N.Y. Acad. Sci. 98:700-711.

29. King, E. O., M. K. Ward, and D. E. Raney. 1964. Two simple media for demonstration of pyocyanin and fluorescin. J. Lab. Clin. Med. 44:301-307.

30. Kingscote, B. 1961. Use of catalase in the culture of Vibrio fetus. Can. J. Microbiol. 7:951-952.

31. Kovacs, N. 1956. Identification of Pseudomonas pyocyanae by the oxidase reaction. Nature (London) 178:173.

32. Krieg, N. R., and P. B. Hylemon. 1976. The taxonomy of the chemoheterotrophic spirilla. Annu. Rev. Microbiol. 30:303-325.

33. Lawson, G. H. K., J. L. Leaver, G. W. Pettigrew, and A. C. Rowland. 1981. Some features of Campylobacter sputorum subsp. mucosalis subsp. nov., nom. rev. and their taxonomic significance. Int. J. Syst. Bacteriol. 31:385-391.

34. Lawson, G. H. K., A. C. Rowland, and P. Wooding. 1975. The characterisation of Campylobacter sputorum subsp. mucosalis isolated from pigs. Res. Vet. Sci. 18:121-126.

35. Leaper, S., and R. J. Owen. 1982. Differentiation between Campylobacter jejuni and allied thermophilic campylobacters by hybridisation of deoxyribonucleic acids. FEMS Microbiol. Lett. 15:203-208.

36. Liston, J., W. Weibe, and R. R. Colwell. 1960. Quantitative approach to the study of bacterial species. J. Bacteriol. 85:1061-1070.

37. Love, D. N., R. J. Love, and M. Bailey. 1977. Comparison of Campylobacter sputorum subspecies mucosalis strains in PIA and PHE. Vet. Rec. 101:407.

38. Marmur, J., S. Falkow, and M. Mandel. 1963. New approaches to bacterial taxonomy. Annu. Rev. Microbiol. 17:329-372.

39. Marshall, B. J., and J. R. Warren. 1983. Spiral bacteria in the human stomach: a common finding in patients with gastritis and duodenal ulcer, p. 11-12. In A. D. Pearson, M. B. Skirrow, B. Rowe, J. R. Davies, and D. M. Jones (ed.), Campylobacter II. Public Health Laboratory Service, London.

40. McFaydean, J., and S. Stockman. 1914. Abortion in sheep, p. 101-137. In Report to the Departmental Committee appointed by the Board of Agriculture and Fisheries to enquire into epizootic abortion. Appendix V, part 3. Cd 7157, XII Board of Agriculture and Fisheries, London.

41. Mohanty, S. P., G. J. Plumer, and J. E. Faber. 1962. Biochemical and colonial characteristics of some bovine vibrios. Am. J. Vet. Res. 23:554-557.

42. Moller, V, 1955. Simplified tests for some amino-acid decarboxylases and for the arginine dehydrolase system. Acta Pathol. Microbiol. Scand. 36:158-172.

43. Neill, S. D., W. A. Ellis, and J. J. O'Brien. 1975. Designation of aerotolerant Campylobacter-like organisms from porcine and bovine abortions to the genus Campylobacter. Res. Vet. Sci. 27:180-186.

44. Neill, S. D., W. A. Ellis, and J. J. O'Brien. 1978. The biochemical characteristics of Campylobacter-like organisms from cattle and pigs. Res. Vet. Sci. 25:368-372.

45. Neill, S. D., W. A. Ellis, and J. J. O'Brien. 1980. The isolation of aerotolerant campylobacter. Vet. Rec. 106:152-153.

46. Owen, R. J., and S. Leaper. 1981. Base composition, size nucleotide sequence similarities of genome deoxyribonucleic acids from species of the genus Campylobacter. FEMS Microbiol. Lett. 12:395-400.

47. Plastridge, W. N., M. E. Koths, and L. F. Williams. 1961. Antibiotic medium for isolation of vibrios from bull semen. Am. J. Vet. Res. 22:867-870.

48. Prevot, A. R. 1940. Etudes de systematique bacterienne. V. Classification des vibrions anaerobies. Ann. Inst. Pasteur Paris 64:117-125.

49. Reich, C. W., E. V. Morse, and A. B. Wilson. 1956. Gaseous requirements for growth of Vibrio fetus. J. Vet. Res. 17:140-143.

50. Rogers, K. B., and J. Taylor. 1961. Laboratory diagnosis of gastroenteritis due to Escherichia coli. Bull. W.H.O. 24:59-71.

51. Sebald, M., and M. Veron. 1963. Base content of DNA and classification of vibrios. Ann. Inst. Pasteur Paris 105:879-910.

52. Skirrow, M. B., and J. Benjamin. 1980. "1001" Campylobacter: cultural characteristics of intestinal campylobacters from man and animals. J. Hyg. 85:427-432.

53. Skirrow, M. B., and J. Benjamin. 1980. Differentiation of 
enteropathogenic campylobacter. J. Clin. Pathol. 33:1121.

54. Smibert, R. M. 1974. Genus II. Campylobacter, p. 207-212. In R. E. Buchanan and N. E. Gibbons (ed.), Bergey's manual of determinative bacteriology, 8th ed. The Williams \& Wilkins Co., Baltimore.

55. Smibert, R. M. 1978. The genus Campylobacter. Annu. Rev. Microbiol. 32:673-709.

56. Smibert, R. M., and A. van Graevenitz. 1980. A human strain of C. fetus spp. intestinalis grown at $42^{\circ} \mathrm{C}$. J. Clin. Pathol. 33:603-604.

57. Smith, T., and M. S. Taylor. 1919. Some morphological and biochemical characters of the spirilla (Vibrio fetus n. sp.) associated with disease of the foetal membranes in cattle. J. Exp. Med. 30:299-311.

58. Sneath, P. H. A., and R. Johnston. 1972. The influence on numerical taxonomic similarities of errors in microbiological tests. J. Gen. Microbiol. 72:377-392.

59. Sneath, P. H. A., and R. R. Sokal. 1973. Numerical taxonomy: the principals and practice of numerical classification. W. H. Freeman and Co., San Francisco.
60. Tanner, A. C. R., S. Badger, C. H. Lai, M. A. Listgargen, R. A. Visconti, and S. S. Socransky. 1981. Wolinella gen. nov., Wolinella succinogenes (Vibrio succinogenes Wolin et al.) comb. nov., and description of Bacteroides gracillis sp. nov., Wolinella recta $\mathrm{sp}$. nov., Campylobacter concisus sp. nov., and Eikenella corrodens from humans with peridontal disease. Int. J. Syst. Bacteriol. 31:432-445.

61. Ursing, J. B., K. Standstedt, and M. Waldor. 1983. DNA homology groups of thermotolerant Campylobacter spp., p. 39. In A. D. Pearson, M. B. Skirrow, B. Rowe, J. R. Davies, and D. M. Jones (ed.), Campylobacter II. Public Health Laboratory Service, London.

62. Véron, N., and R. Chatelain. 1973. Taxonomic study of the genus Campylobacter Sebald and Veron and designation of the neotype strain for the type species, Campylobacter fetus (Smith and Taylor) Sebald and Veron. Int. J. Syst. Bacteriol. 23:122-134.

63. Weatherup, S. T. C. 1980 . Statistical procedures for distinctness, uniformity and stability variety trials. J. Agric. Sci. 94:31-46. 